\title{
Structure, Bonding, and Mineralogy of Carbon at Extreme Conditions
}

\author{
Artem R. Oganov \\ Department of Geosciences \\ State University of New York \\ Stony Brook, New York 11794-2100, U.S.A. \\ artem.oganov@stonybrook.edu \\ Russell J. Hemley, Robert M. Hazen \\ Geophysical Laboratory, Carnegie Institution of Washington, \\ 5251 Broad Branch Road NW \\ Washington, DC 20015, U.S.A. \\ rhemley@ciw.edu rhazen@ciw.edu \\ Adrian P. Jones \\ Depatment of Earth Sciences, University College London \\ Gower Street, London WC1E 6BT United Kingdom \\ adrian.jones@ucl.ac.uk
}

\section{INTRODUCTION}

The nature and extent of Earth's deep carbon cycle remains uncertain. This chapter considers high-pressure carbon-bearing minerals, including those of Earth's mantle and core, as well as phases that might be found in the interiors of larger planets outside our solar system. These phases include both experimentally produced and theoretically predicted polymorphs of carbon dioxide, carbonates, carbides, silicate-carbonates, as well as very high-pressure phases of pure carbon. One theme in the search for possible high $P$ - $T$, deep-Earth phases is the likely shift from $s p^{2}$ bonding (trigonal coordination) to $s p^{3}$ bonding (tetrahedral coordination) in carbon-bearing phases of the lower mantle and core, as exemplified by the graphite-to-diamond transition (Bundy et al. 1961; Davies 1984). A similar phenomenon has been documented in the preferred coordination spheres of many elements at high pressure. For example, silicon is ubiquitously found in tetrahedral coordination in crustal and upper mantle minerals, but adopts octahedral coordination in many high-pressure phases. Indeed, the boundary between Earth's transition zone and lower mantle may be described as a crystal chemical shift from 4-coordinated to 6-coordinated silicon (Hazen and Finger 1978; Finger and Hazen 1991). Similarly, magnesium and calcium commonly occur in octahedral 6-coordination in minerals at ambient conditions, but transform to 8- or greater coordination in high-pressure phases, as exemplified by the calcite-to-aragonite transformation of $\mathrm{CaCO}_{3}$ and the pyroxene-toperovskite and post-perovskite transformations of $\mathrm{MgSiO}_{3}$ (Murakami et al. 2004; Oganov and Ono 2004). Consequently, a principal focus in any consideration of deep-Earth carbon minerals must include carbon in higher coordination, and even more complex bonding at more extreme conditions that characterize the interiors of larger planets. 


\section{THEORETICAL CONSIDERATIONS}

We briefly review theoretical methods used to examine dense carbon-bearing minerals, focusing on first-principles or ab initio approaches. To compute the energies, one can choose one among a hierarchy of theoretical approximations. The energetics of the phases considered in this chapter have also been studied using quantum chemistry methods. These approaches have been applied, for example, to pure carbon phases (Guth 1990; Che et al. 1999). A leading approach is density functional theory (Hohenberg and Kohn 1964; Kohn and Sham 1965), which in principle is an exact quantum-mechanical theory, but in practice requires approximations, such as the LDA (local density approximation: Perdew and Wang 1992). Early LDA calculations proved successful in predicting the high-pressure behavior of carbon (e.g., Fahy et al. 1986; Fahy and Louie 1977).

Recent extensions of the LDA include GGA (generalized gradient approximation: Perdew et al. 1996), meta-GGA (Tao et al. 2003), or higher-level approximations currently under development. The only approximate term in the equations is the exchange-correlation energy (the non-classical part of the electron-electron interaction energy), the most successful approximations of which are based on the properties of the electron gas, with more advanced approximations taking into account more non-local features, for example, gradient, Laplacian, or orbital kinetic energy density. The usual accuracy of such approximations as LDA and GGA is on the order of $1-2 \%$ for bond lengths and unit-cell parameters, where LDA usually underestimates and GGA overestimates bond lengths; 15\% for the elastic constants; and $~ 5 \%$ for vibrational frequencies. For phase transitions and chemical reactions, the GGA seems to perform much better than the LDA, with phase transition pressures accurate to within $\sim 5 \mathrm{GPa}$ (usually overestimated); however, for metal-insulator transitions errors of both approximations are typically much larger. For ionic and covalent materials and for normal metals (carbon allotropes and most carbonates and perhaps carbides belong to these classes) both LDA and GGA give good description of the structural properties and thermodynamics. Large errors in all compounds are documented for calculations of electronic excitation energies and band gaps (both LDA and GGA significantly underestimate band gaps); one must employ special methods, such as the $G W$ method (Aryasetiawan and Gunnarsson 1998), to compute these parameters. Mott insulators represent a particular pathological case, where today's DFT too often gives unreasonable results. Until recently, DFT calculations could not adequately account for van der Waals interactions, but ways for incorporating these effects are now possible (Dion et al. 2004; Roman-Perez and Soler 2009).

Given the high degree of thermodynamic equilibrium reached in Earth's deep interior due to high temperatures and long geological timescales, it often suffices in studies of mantle and core mineralogy to consider free energies of relevant chemical equilibria without accounting for kinetics. The Gibbs free energy $G$ of a particular phase can be calculated as:

$$
G=E+P V-T S=F+P V=F-V\left(\frac{\partial F}{\partial V}\right)_{\mathrm{T}}
$$

where $P$ is the pressure, $V$ the volume, $T$ the temperature, $S$ the entropy, $F$ is the Helmholtz free energy, $E_{0}$ is the ground-state energy (at $0 \mathrm{~K}$ ), and $E n$ are the energy levels of the system:

$$
F=E_{0}-k_{\mathrm{B}} T \ln \sum_{n} e^{-E_{a} / k_{B} T}
$$

The sum within the logarithm in Equation (2) is called the partition function, and its rigorous calculation is complicated owing to the difficulty in obtaining energy levels experimentally or theoretically for their overwhelmingly large number in solids. In the simplest, harmonic approximation these energy levels are: 


$$
E_{n}=\hbar\left(\frac{1}{2}+n\right) \omega
$$

where $n$ is the quantum number, $\omega$ the frequency of the vibration, and $\hbar$ is the Planck constant. More sophisticated approximations exist, but the general point is that knowledge of the energy landscape allows one to compute all thermodynamic properties, including the entropy.

Predicting the most stable structure is a global optimization problem, and such problems are mathematically said to be of the NP-hard class and cannot be solved with a guarantee. To deal with such problems, one develops heuristic methods, the goal of which is to achieve high success rate and efficiency for a given class of problems. A variety of methods exists for predicting structures (e.g., Martoňák et al. 2003; Oganov and Glass 2006; Oganov et al. 2010; Pickard and Needs 2011; for an overview of different methods see Oganov 2010). A large number of results for carbon-bearing phases under pressure (Oganov et al. 2006, 2008; Li et al. 2009; Lyakhov and Oganov 2011; Wen et al. 2011; Zhu et al. 2011, 2012a; Bazhanova et al. 2012) have been obtained with the evolutionary algorithm USPEX (Oganov and Glass 2006; Oganov 2010; Lyakhov et al. 2010; Oganov et al. 2011).

A powerful computational method called evolutionary metadynamics has recently been developed by Zhu et al. (2012a). This method, which merges features of the USPEX method and metadynamics (Martoňák et al. 2003), is capable of rapidly finding the ground state structure and a large number of low-energy metastable structures, provided a reasonable initial structure. As in the original metadynamics method, the new method produces meaningful structural transformation mechanisms. However, equilibration is achieved not using molecular dynamics, which is prone to trapping in metastable states and often leads to amorphization during metadynamics simulations, but rather employs global optimization moves borrowed from the USPEX method. Unlike original metadynamics, this technique produces extremely rich sets of low-energy crystal structures, while using less computer time. Particularly attractive is a possibility to determine the most likely crystal structures accessible from the initial structure through metastable transitions.

\section{ELEMENTAL CARBON}

One of the remarkable features of carbon is existence of a broad range of metastable phases that can be formed near ambient conditions and their wide fields of kinetic stability. We consider both stable and metastable phases (Fig. 1) as well as both equilibrium and metastable transitions among the phases, and predictions of carbon allotropes at very high pressures beyond those of Earth. This section includes a discussion of metastable transitions of the lower density phase. Not only do these structures provide useful insight into carbon crystal chemistry and bonding, but transitions to these phases also may be relevant to natural impact phenomena involving these phases in nature.

\section{Stable phases}

The common naturally-occurring $s p^{2}$ and $s p^{3}$ allotropes of carbon occur in different crystallographic forms of graphite-like and diamond-like phases, respectively: hexagonal graphite and a rhombohedral stacking variant; as well as hexagonal lonsdaleite and cubic diamond (see Hazen et al. 2013). The large cohesive energy of diamond $(717 \mathrm{~kJ} / \mathrm{mol}$ ), together with significant energy barriers, gives rise to its high degree of metastability and extremely high melting temperature $(5000 \mathrm{~K})$. The high activation barrier for a transformation between graphite and diamond explains why synthesis of diamond from graphite requires not only high pressures, but also high temperatures and often the presence of catalysts. 


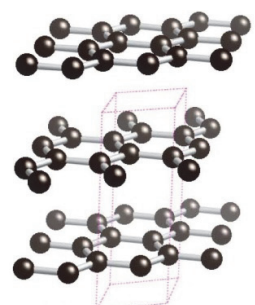

graphite

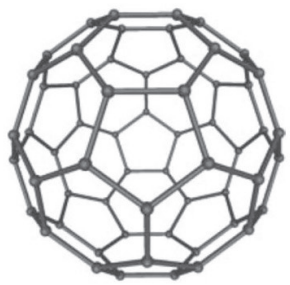

fullerene

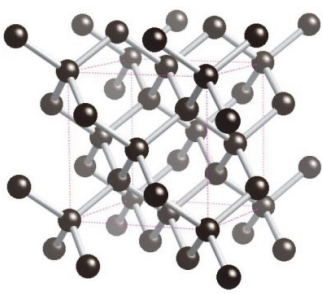

diamond

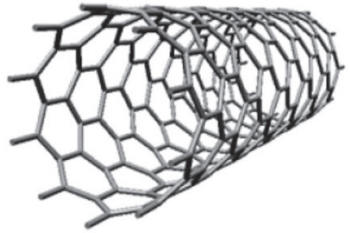

nanotube

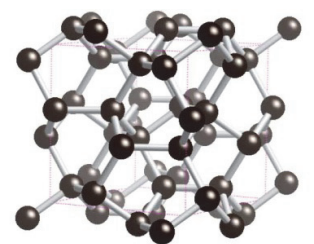

$\mathrm{BC} 8$

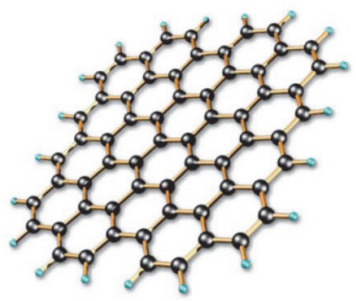

graphene

Figure 1. Structures of selected allotropes of carbon.

The structures and occurrences of naturally existing carbon allotropes, including graphite, diamond, and lonsdaleite, are reviewed elsewhere in this volume (Hazen et al. 2013). Here we focus on phase transitions in graphite. The graphite melting line at low pressures is now well established (Ludwig 1902; Basset 1939; Jones 1958; Gathers et al. 1974a,b; Kirillin et al. 1984; Savvatimskiy 2005; Scheindlin and Senchenko 1988; Fig. 2).

Since the original measurements of the compressibility (Adams 1921) and vibrational spectrum (Ramaswamy 1930; Raman 1961), the physical properties of carbon allotropes have been well determined over the range of conditions relevant to Earth's interior. For example, there is excellent agreement on the value of diamond's very high bulk modulus (440 $\mathrm{GPa}$ at $300 \mathrm{~K}$ ) from a variety of experimental and theoretical techniques (Occelli et al. 2003). The singular strength of diamond correlates with its very high shear modulus (535 GPa at $300 \mathrm{~K}$ ), which exceeds the bulk modulus (a phenomenon observed in only a few materials: Brazhkin et al. 2002). Theoretical methods now accurately reproduce the elastic properties of diamond and provide robust predictions of their variations over the entire $P-T$ range of Earth's interior (Nuñez Valdez et al. 2012). The electronic properties of diamond are now well determined experimentally (Endo et al 2001), and there is excellent agreement with electronic structure calculations. On the other hand, the anharmonic properties of diamond are not fully understood (Gillet et al. 1998). The initial slope of the diamond melting line was for many years controversial, but now seems well established and has a positive value (Bundy et al. 1996). Recent very high $P$ - $T$ shock wave experiments indicate a maximum in the melting line near 1.5 $\mathrm{TPa}$ (Knudson et al. 2008; Eggert et al. 2010; Fig. 3). Early first-principles calculations (Galli et al. 1989) indicated that liquid carbon at low pressure and $5000 \mathrm{~K}$, should have mainly two-fold and three-fold coordination. Theoretical studies of the carbon melting curve have continued to super-Earth conditions beyond the stability of diamond (see Correa et al 2006).

The types and concentrations of defects present in the material remain subjects of study (Gabrysch 2008). Recent advances in analytical methods confirm that most mantle diamonds 


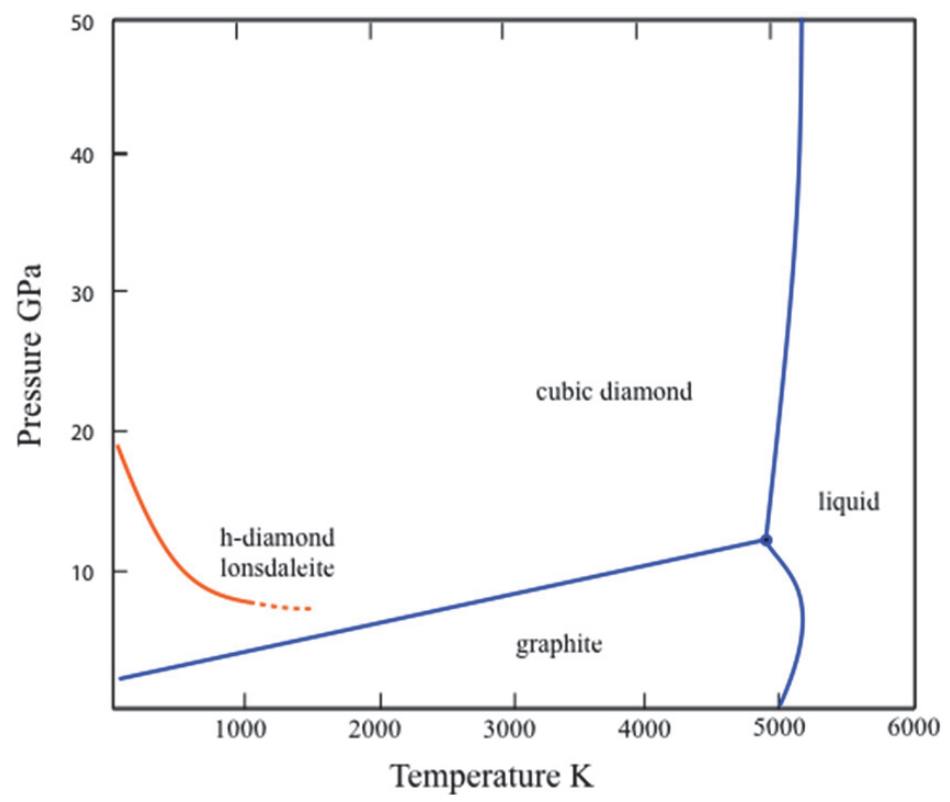

Figure 2. Phase diagram for carbon in Earth to $50 \mathrm{GPa}$ (approximately $1500 \mathrm{~km}$ depth), showing the classic diamond-graphite line and field for liquid; note the liquidus for diamond has positive $d P / d T$ consistent with calculations to higher pressure, and the only significant change to the early curve of Bundy et al. (1996). The red curve marks the metastable lonsdaleite or hexagonal (h-) diamond transition from Utsumi et al. (1996). At $P-T$ conditions close to this red curve and above $\sim 1070 \mathrm{~K}\left(800{ }^{\circ} \mathrm{C}\right)$, h-diamond from graphite is quenchable and recoverable, whereas below $\sim 1070 \mathrm{~K}, \mathrm{~h}$-diamond is unquenchable. The form of graphite used in the experiments has some influence, and additional metasatable complications for h-diamond are not yet fully understood (see Utsumi and Yagi 1991; Utsumi et al. 1994). Lonsdaleite is associated with formation in terrestrial impact craters and meteorites (see review in Ross et al. 2011) and has recently been discovered in ultrahigh pressure (UHP) metamorphic rocks (Godard et al. 2012).

are very pure except for variable low concentrations of nitrogen. McNeill et al. (2009) analyzed a suite of 10 diamonds from the Cullinan Mine (previously known as Premier), South Africa, along with other diamonds from Siberia (Mir and Udachnaya) and Venezuela. The concentrations of a wide range of elements for all the samples (expressed by weight in the solid) are very low, with rare earth elements along with $\mathrm{Y}, \mathrm{Nb}$, and $\mathrm{Cs}$ ranging from 0.01 to 2 ppb. Large ion lithophile elements (LILE) such as $\mathrm{Rb}$ and $\mathrm{Ba}$ vary from 1 to $30 \mathrm{ppb}$. Ti ranges from ppb levels up to $2 \mathrm{ppm}$.

The graphite-to-diamond and graphite-to-lonsdaleite transitions have been intensely investigated (see Hazen 1999; Hazen et al. 2013). The position of the diamond/graphite equilibrium line has been quite accurately established by thermodynamic calculations based upon the measured physical properties of graphite and diamond in the temperature range from 300 to about 1200 K (Rossini and Jessup 1938; Leipunskii 1939; Berman and Simon 1955; Day 2012) and by experiments on growing or graphitization of diamond (Bundy et al. 1961; Kennedy and Kennedy 1976). Shock compression experiments on hexagonal graphite particles yield mostly hexagonal diamond (e.g., Kudryumov et al. 2012), whereas in natural impact events, kinetics and grain size can influence the survival of lonsdaleite (DeCarli et al. 2002a). 


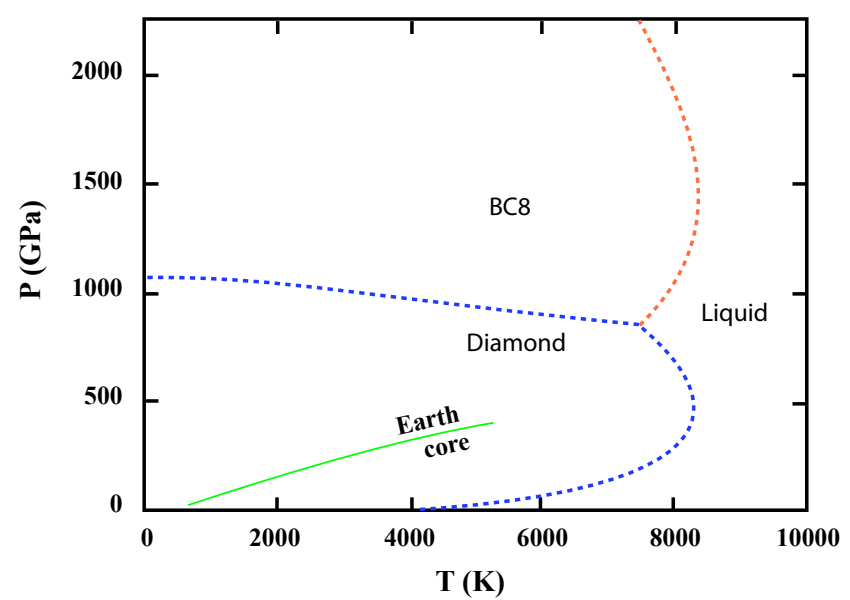

Figure 3. Calculated phase relations for diamond to super Earth conditions. Above $1000 \mathrm{GPa}$ diamond is displaced by $\mathrm{BC} 8$. The green line marks the terrestrial geotherm (approximate), along which the maximum pressure at Earth's center corresponds to $\sim 360 \mathrm{GPa}$ in the inner core. Note that diamond is stable to approximately twice the pressure at Earth's center and does not melt below 5000 K. Diamond is expected to be a planetary "survivor of catastrophe," such as the Moon-forming collision on Earth. Diagram based on Correa et al (2006). Note that on this diagram with extreme pressure range, the field for graphite is too small to depict (but tracks along the low-pressure axis).

\section{Metastable phases}

Because of the high cohesive and activation energy, carbon allotropes typically exist metastably well into a $P$ - $T$ region where a different solid phase is thermodynamically stable. For example, diamond survives indefinitely at room conditions, where graphite is the thermodynamically stable form. The metastability of diamond may also persist to very high pressures, well into the stability field of higher-pressure phases. We also mention that studies of metastable growth of diamond within Earth continue, though the mechanism is not well understood (Simakov 2012). It is also useful to point out that diamond can be easily produced outside of its stability field (e.g., by chemical vapor deposition), and that it can exhibit striking properties (Hazen 1999). For example, measurements show that the material has much higher toughness than natural diamond (Liang et al. 2009; Pan et al. 2009). Similarly, the natural hexagonal diamond or lonsdaleite (Bundy and Kasper 1967; Lonsdale 1971) is becoming increasingly recognized in both meteoritic and terrestrial materials (Ross et al. 2011; Shumilova et al. 2011), yet its occurrence cannot be interpreted in terms of origin, since fundamental understanding of its metastability remains unresolved (Godard et al. 2012; Kurdyumov et al. 2012).

Metastable allotropes of carbon include fullerenes, nanotubes, and graphene, as well as disordered or amorphous forms, such as glassy carbon and carbon black and possibly metastable solid forms referred to as carbynes (see Hazen et al. 2013, Table 1). The synthesis of carbynes ( $s p$ hybridized allotrope) has been reported (Kasatochkin et al. 1967; Chalifoux and Tykwinski 2010), but this finding remains controversial.

The proclivity of carbon to form well-defined kinetically stable structures persists at extreme conditions. For example, it has long been known that if graphite is compressed to $~ 15$ $\mathrm{GPa}$ at low temperature (e.g., room temperature or below) it transforms to a different allotrope of carbon that is distinct from diamond (Aust and Drickamer 1963; Hanfland et al. 1989; Zhao and Spain 1989; Miller et al. 1997; Utsumi and Yagi 1991; Yagi et al. 1992; Mao et al. 2003). The phase was found to exhibit unusual properties. For example, Goncharov (1990) found 
that the transition pressure for single-crystal graphite can be lowered to about $14 \mathrm{GPa}$ under uniaxial stress directed along the $c$-axis of the crystal. These Raman and optical observations were corroborated by Hanfland et al. (1989) and Utsumi et al. (1993). Hanfland et al. (1990) showed that the phase transition started at about 14 GPa using X-ray diffraction and Raman spectroscopy. The phase formed from single-crystal graphite was found to be transparent, and Miller et al. (1997) quenched the transparent form at low temperatures. X-ray Raman and diffraction measurements reported by Mao et al. (2003) showed mixed $s p^{2}$ and $s p^{3}$ bonding but the structure could not be determined. The phase was also found to be superhard (Fig. 4). Very recently, Wang et al. (2012b) used X-ray diffraction, Raman spectroscopy, and optical techniques to examine this phase.

Early calculations of the structure formed from compression of graphite were carried out by Kertesz and Hoffmann (1984) and Fahy et al. (1986). This metastable transition has been the subject of more recent theoretical studies. Using USPEX, Oganov and Glass (2006) found a number of interesting low-energy metastable carbon allotropes, among which was a monoclinic (space group $C 2 / m$ ) structure with tetrahedral coordination ( $s p^{3}$ hybridization) of carbon atoms, and this structure contained 5- and 7-fold rings (Fig. 5). The structure

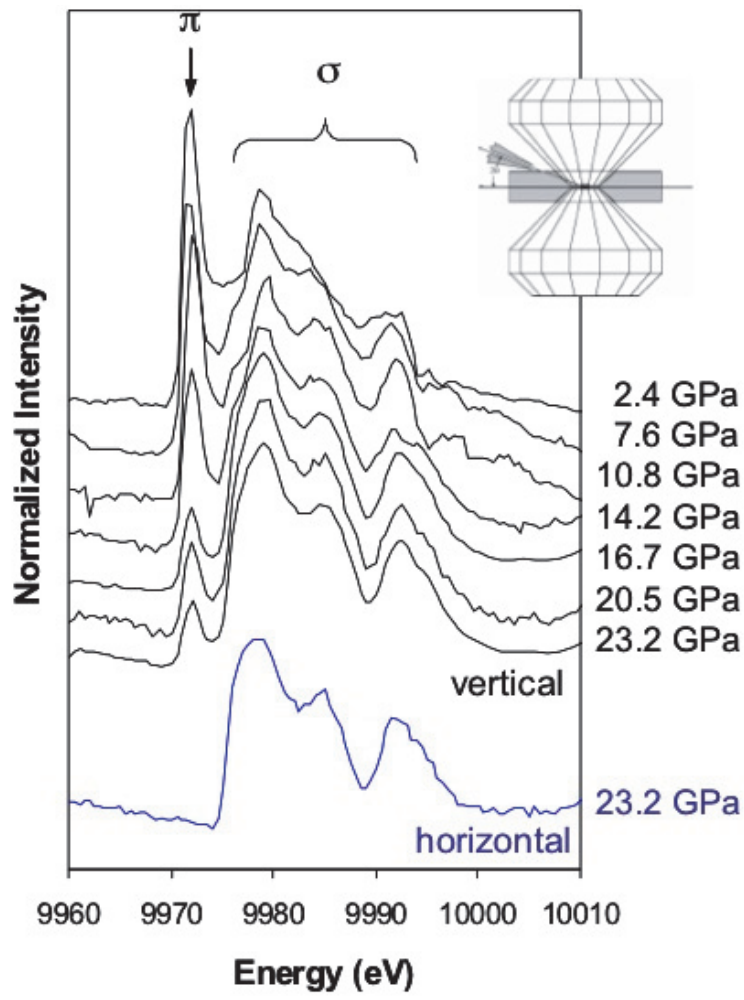

Figure 4. X-ray Raman spectra of graphite under pressure. The lower energy peak, labeled $\pi$, corresponds to $1 \mathrm{~s}$ to $\pi^{*}$ transitions and the higher energy portion, labeled $\sigma$, corresponds to $1 \mathrm{~s}$ to $\sigma^{*}$ transitions. The bottom spectrum, taken in the horizontal direction, probes bonds in the $a$ plane, and the top spectra, taken in the vertical direction, probe the $c$ plane. The inset shows the geometry of the diamond anvil cell experiment. The spectra reveal the development of mixed $\pi$ and $\sigma$ bonding in the high pressure phase formed by compression of graphite [Adapted with permission of The American Association for the Advancement of Science from Mao et al. (2003) Science, Vol. 302, p. 425-427, Fig. 1.] 


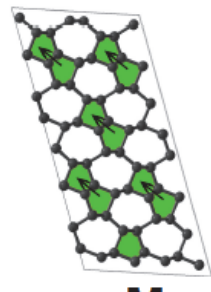

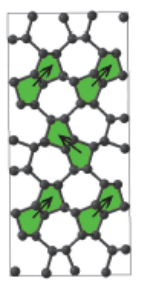

W bct-C4

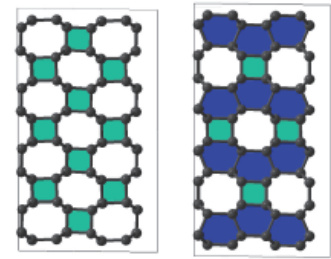

$\mathbf{Z}$
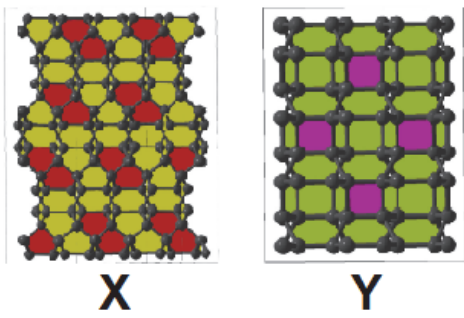

Figure 5. Calculated high-pressure metastable $s p^{3}$ structures of elemental carbon. [Used with permission of the American Physical Society from Zhu et al. (2012b) Phys Rev B, Vol. 85, 201407, Figs. 2c-f and 4a,b. http://link.aps.org/doi/10.1103/PhysRevB.85.201407]

has a 2D-analog: $(2 \times 1)$-reconstructions of the (111) surfaces of diamond and silicon. Li et al. (2009) subsequently named this structure M-carbon (because of its monoclinic symmetry) and identified it as the "superhard graphite," based on the close match between theoretical and experimental diffraction data. The bct- $\mathrm{C}_{4}$ structure (Baughman et al. 1997; Umemoto et al. 2010; Zhou et al. 2010) was proposed as an alternative, and that was shortly followed by descriptions of hypothetical W-carbon (Wang et al. 2011) and Z-carbon (Zhao et al. 2011; Amsler et al. 2012), as well as further structures (e.g., Selli et al. 2011; Niu et al. 2012). It is notable also that while Amsler et al. (2012) proposed Z-carbon to explain experimental measurements on "superhard graphite," Zhao et al. (2011) concluded that its X-ray diffraction is incompatible with experimental data on "superhard graphite," but can explain experimental data on over-compressed carbon nanotubes (Wang et al. 2004). With two evolutionary metadynamics simulations starting from graphite-2H and graphite-3R, Zhu et al. (2012b) found all of these structures and several new ones. All of these structures are metastable, superhard, and insulating; they all become more stable than graphite under pressure ( 7 to $27 \mathrm{GPa}$ ); they all contain carbon entirely in the tetrahedral coordination; and they all have buckled graphene sheets, suggesting possible mechanism of formation of these phases from graphite. Although more than a dozen different crystal structures have been suggested for the phase, the proposed low-symmetry, monclinic, M-carbon structure (Oganov and Glass 2006; Li et al. 2009) is the only one that fits the highest resolution high-pressure data, reported by Wang et al. (2012b).

Theory can discriminate between proposed high-pressure metastable structures and provide insights into the transition. The metastable high-pressure phase is formed solely because it has the lowest activation barrier at the indicated $P$ - $T$ conditions (e.g., $15 \mathrm{GPa}$ and $300 \mathrm{~K}$ ). Using transition path sampling (Dellago et al. 1998; Leoni and Boulfelfel 2010; Boulfelfel et al. 2012) found that the likeliest $s p^{3}$ structure of carbon to be formed by room-temperature compression of graphite- $2 \mathrm{H}$ is indeed M-carbon. Boulfelfel et al. (2012) predict this transition has a lower energy barrier than transitions to other structures. The transition involves bending of graphene layers and formation of bonds between them-a mechanism that leads to the peculiar geometry of M-carbon with 5-and 7-fold rings. Shortly after this definitive theoretical confirmation of M-carbon, a definitive experimental confirmation followed (Wang et al. 2012b).

\section{Fullerenes at pressure}

We now consider transitions and structures formed from metastable low-pressure fullerene-related phases. The ambient phase of $\mathrm{C}_{60}$ has the high-symmetry face-centered cubic $(f c c)$ structure. Reversible transitions are observed at low $P$ - $T$ conditions (see Hemley and Dera 2000). Under hydrostatic conditions the $f c c$ structure of solid $C_{60}$ remains kinetically stable to pressures of $20 \mathrm{GPa}$, whereas non-hydrostatic stress induces a phase transition to a new phase of lower symmetry (Duclos et al. 1991). Further studies revealed that non-hydrostatic 
compression of $\mathrm{C}_{60}$ induces the formation of diamond (Núñez-Regueiro et al. 1992) and other related structures above $15 \mathrm{GPa}$ (Sundqvist 1999). Compression increases the possibility of interaction between the double bonds on nearest neighbor molecules, which results in the formation of polymers (Marques et al. 1996; Sundqvist 1999). He and Ne can be introduced into fullerene cages (see Saunders et al. 1996). The extent to which this could lead to the possibility of trapping gases under pressure in planetary interiors remains to be investigated.

Recently, Wang et al. (2012a) reported a long-range ordered material constructed from units of amorphous carbon clusters synthesized by compressing solvated fullerenes. Using $\mathrm{X}$-ray diffraction, Raman spectroscopy, and quantum molecular dynamics simulation, they observed that, although $\mathrm{C}_{60}$ cages were crushed and became amorphous, the solvent molecules remained intact, playing a crucial role in maintaining the long-range periodicity. Once formed, the high-pressure phase is quenchable back to ambient conditions. The phase has very high strength, producing ring cracks in the diamond anvils used in the experiment (as does the phase produced from graphite; Mao et al. 2003).

\section{Ultrahigh-pressure phases}

A number of studies through the years have addressed the question of the upper limits of the diamond stability field and possible post-diamond phases. Experimental data in this $P-T$ regime have been obtained by dynamic compression. Early LDA calculations by Fahy and Louie (1987) predicted that at pressures above $1 \mathrm{TPa}$ diamond transforms to the so-called BC8 structure-an unusual tetrahedral structure that has been observed as a metastable state of silicon (Kasper and Richards 1964). Their total energy calculations (Fahy and Louie 1987) showed that diamond becomes less stable than the BC8 structure, but more stable structures could not be excluded. Evolutionary crystal structure prediction simulations (Oganov and Glass 2006) confirmed their conclusion that above $1 \mathrm{TPa}$ the BC8 structure of carbon is thermodynamically stable. Other theoretical calculations, together with existing shock-wave data, are consistent with these predictions for BC8 (Knudson et al. 2008). Martinez-Canales et al. (2012) employed DFT methods to examine structures with up to 12 carbon atoms per unit cell at pressures between $1 \mathrm{TPa}$ and 1 petapascal $(1000 \mathrm{TPa})$. They propose a sequence of denser carbon allotropes: The BC8 phase is predicted to transform to the simple cubic structure at $2.9 \mathrm{TPa}$, followed by a soft-phonon transition to a simple hexagonal structure at $6.4 \mathrm{TPa}$, the electride $f c c$ structure at $21 \mathrm{TPa}$, a double hexagonal close-packed (hcp) structure at $270 \mathrm{TPa}$, and ultimately a body-centered cubic $(b c c)$ structure at $650 \mathrm{TPa}$. It is now possible to explore these ultrahigh-pressure regimes with dynamic compression techniques using megajoule class lasers such as the National Ignition Facility (NIF; e.g., Smith 2011).

\section{CARBIDES}

Carbides of iron have been considered as potentially significant components of Earth's core based on early comparisons with meteoritic iron (Ringwood 1960; Lovering 1964; Ahrens 1982; Hazen et al. 2013) and the requirement for a light alloying element to match observed core densities (Birch 1964; Wood et al. 2013). The stoichiometry of high-pressure Fe-carbide is uncertain; if $\mathrm{Fe}_{7} \mathrm{C}_{3}$ is more stable than $\mathrm{Fe}_{3} \mathrm{C}$, then up to $1.5 \%$ carbon could be present in the inner core (Mookherjee 2011; Mookherjee et al. 2011). The incorporation of carbon in the fluid outer core has been studied based on extrapolations from low $P-T$ data as well as various theoretical techniques (Terasaki et al. 2010; Zhang and Yin 2012; and references therein). The widespread existence of carbides in Earth's silicate mantle (particularly Fe-carbide) has been predicted for depths $>250 \mathrm{~km}$ based on experimentally determined $f_{\mathrm{O}_{2}}$ conditions (Frost et al. 2004; Rohrbach et al. 2007, 2010; Frost and McCammon 2008; Rohrbach and Schmidt 2011; Stagno and Frost 2011) and the reactivity of carbon and iron at high pressures and temperatures (Rouquette et al. 2008; Oganov et al 2008; Lord et al. 2009). 
Mantle iron carbide stability is illustrated schematically in Figure 6 as a function of depth and oxygen fugacity. Despite the prediction for abundant Fe-carbides in the mantle, terrestrial occurrences are very rare, and are typically associated with diamond. Fe-carbides have been documented as inclusions within diamonds from Jagersfontein, South Africa (Jones at al. 2008); Juina, Brazil (Kaminsky and Wirth 2011); and the $23^{\text {rd }}$ Party Congress Kimberlite, Russia (Bulanova and Zayakina 1991). Scarce occurrences of "native iron" inclusions in diamond (Stachel et al. 1998; Bulanova et al. 2010) likely include unrecognized Fe-carbide. Other fragmentary evidence to support carbide in the mantle includes unique spherical micro-inclusions of Fe-carbide ("cohenite") observed in garnet intergrowths from polycrystalline mantle diamond (Jacob et al. 2004). The mantle Fe-rich carbide compositions from Jagersfontein are the most numerous and show limited compositional variation of ( $\mathrm{Fe}-\mathrm{Ni}-\mathrm{Cr}$ ) with minor constituent silicon and trace Co (Table 1; Fig. 7; Hazen et al. 2013). Chemically these mantle carbides appear to be mixtures of various end members like haxonite $\left[\left(\mathrm{Fe}, \mathrm{Ni}_{23} \mathrm{C}_{6}\right]\right.$ and isovite $\left[(\mathrm{Cr}, \mathrm{Fe})_{23} \mathrm{C}_{6}\right]$, but there is no experimental information on their phase relations at high-pressure mantle conditions.

The equation of state and elastic constants of cohenite have been studied to at least 187 GPa (Scott et al. 2001; Fiquet et al. 2009; Sata et al. 2010). Theoretical studies employing the random sampling approach by Weerasinghe et al. (2011) suggest that at inner core pressures (330 to $364 \mathrm{GPa}$ ) cohenite transforms to a denser orthorhombic $\mathrm{Cmcm}$ structure. Evolutionary

\section{Solid carbon speciation in ambient pyrolite}

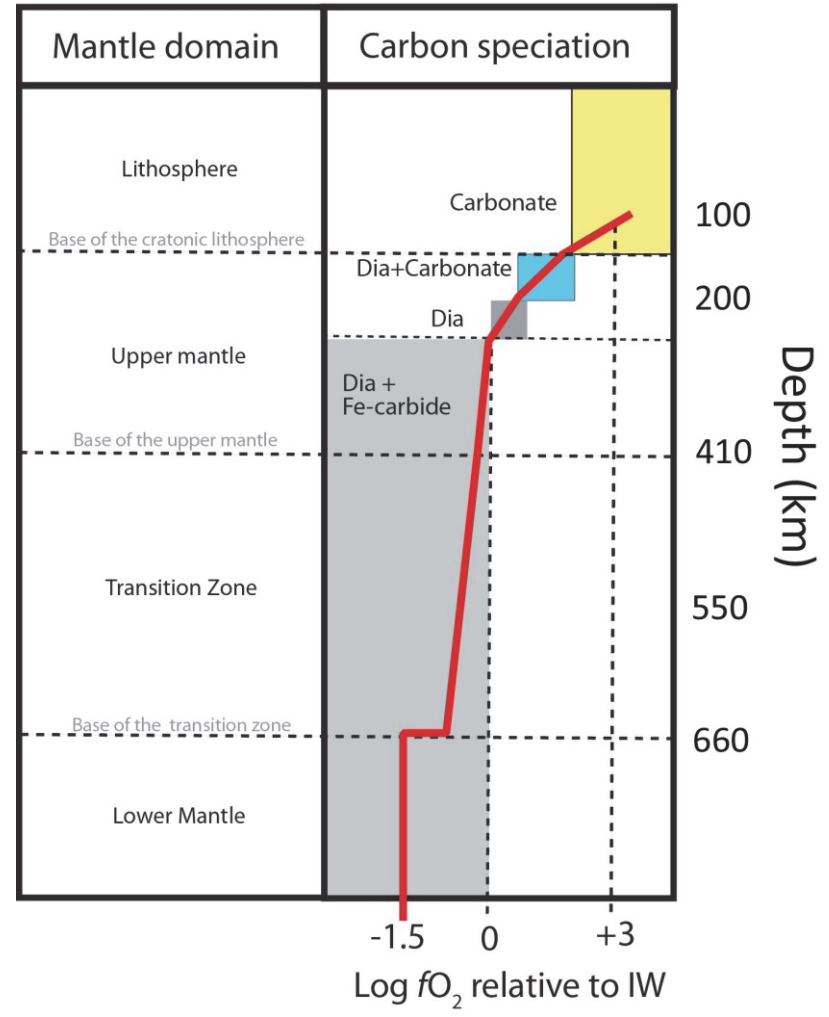

Figure 6. The speciation of carbon as a function of $f_{\mathrm{O}_{2}}$ with depth in an ambient pyrolitic mantle (Mikhail et al. 2011; Rohrbach and Schmidt 2011). Note the dominance in the terrestrial mantle for reduced carbon species relative to carbonate. 


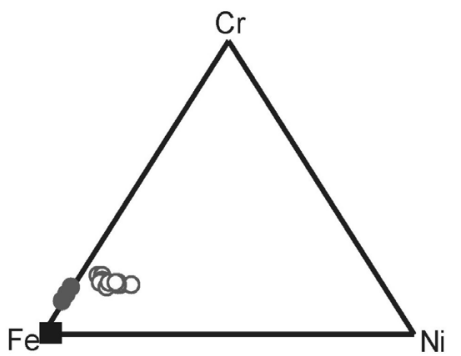

Figure 7. Plot of Fe-Ni-Cr compositions of mantle carbide inclusions within diamond at Jagersfontein, based on electron microprobe analyses (after Jones et al. 2008). Different diamonds can host different carbide compositions: solid red circles $=$ Jag1 $(n=9)$, open blue circles $=\operatorname{Jag} 2(n=5)$ and solid black square $(\operatorname{Jag} 10 n$ $=17$ ). These carbides also contain minor $\mathrm{Co}, \mathrm{Si}$ and $\mathrm{O}$ (see Table 1).

Table 1. Mantle carbide compositions (weight percent, analyzed by WDS electron microprobe) of inclusions in diamond from Jagersfontein (Jones et al. 2008), from microspherules from garnet in polycrystalline diamond from Venetia (average Jacob et al. 2004), compared with theoretical compositions for cohenite, and cementite, and natural "cohenite" from enigmatic crustal basaltic rocks at Disko (Goodrich and Bird 1985; see also Bird et al. 1981 and Jones et al. 2005).

\begin{tabular}{lcccccccc}
\hline & Jag b20 & Jag b26 & Jag $\mathbf{5}$ & Jag 10 & $\begin{array}{c}\text { Venetia } \\
\text { (Average) }\end{array}$ & Cohenite & Cementite & $\begin{array}{c}\text { Disko } \\
\text { “cohenite” }\end{array}$ \\
\hline $\mathbf{F e}$ & 65.43 & 80.92 & 88.42 & 90.28 & 90.41 & 54.92 & 94.73 & $90.7-93.4$ \\
$\mathbf{C r}$ & 15.07 & 8.99 & 2.04 & 0.02 & n.a. & 0 & 0 & n.a. \\
$\mathbf{N i}$ & 9.32 & 0.4 & 0.33 & 0.1 & 1.61 & 28.86 & 0 & $0.7-3.1 *$ \\
$\mathbf{C o}$ & 0 & 0 & 0.21 & 0.18 & 0.37 & 9.66 & 0 & $0.4-0.7$ \\
$\mathbf{S i}$ & 0.78 & 0.55 & 1.65 & 0.78 & 0.03 & 0 & 0 & n.a. \\
$\mathbf{S}$ & 0.14 & 0.06 & 0.02 & 0.07 & 0.21 & 0 & 0 & n.a. \\
$\mathbf{A l}$ & 0.43 & 0.02 & 0.15 & 0.07 & n.a. & 0 & 0 & n.a. \\
$\mathbf{O}$ & 2.08 & 1.55 & 0.97 & 3.99 & n.a. & 0 & 0 & n.a. \\
$\mathbf{C}$ & 5.32 & 6.21 & 5.86 & 4.51 & 6.53 & 6.56 & 5.27 & $5.2-7.2$ \\
Total & 98.57 & 98.70 & 99.44 & 100 & & 100 & 100 & \\
\hline
\end{tabular}

structure prediction simulations (Bazhanova et al. 2012) found an even more stable structure with space group $I \overline{4}$, which at $0 \mathrm{~K}$ is stable in the pressure range 310 to $410 \mathrm{GPa}$. Both the random sampling study (Weerasinghe et al. 2011) and the evolutionary prediction (Bazhanova et al. 2012) agree that at inner core pressures $\mathrm{Fe}_{3} \mathrm{C}$ is not thermodynamically stable. Rather, $\mathrm{Fe}_{2} \mathrm{C}$ with the Pnma space group appears to be the most stable iron carbide at pressures of Earth's inner core. Bazhanova et al. (2012) found that incorporation of $\sim 13$ mol\% carbon into the inner core leads to perfect matching of its density, which sets the upper limit for the carbon content of the core. More complex chemistries (e.g., ternary phase) remain to be studied using these techniques. In addition, it would be useful to examine higher $P-T$ conditions relevant to super-Earths. We note that mixed metal carbides exhibit interesting electronic properties such as superconductivity [e.g., $\mathrm{MgC}_{x} \mathrm{Ni}_{3}(x \approx 1)$, which has a perovskite structure (He et al. 2001)].

\section{MOLECULAR FRAMEWORK STRUCTURES}

\section{Carbon dioxide}

A number of molecular solids may play a role in carbon mineralogy, both at low temperatures and at high pressures (Hemley and Dera 2000). The crystalline phases of carbon dioxide exemplify the potential for varied crystal chemical contexts. The familiar lowtemperature phase of carbon dioxide, also known as "dry ice," incorporates isolated linear $\mathrm{CO}_{2}$ 
molecules in a cubic structure (space group Pa3, $a \sim 5.5 \AA$ ), with 4 linear $\mathrm{CO}_{2}$ molecules per unit cell (Keesom and Köhler 1934; Aoki et al. 1994). Structure refinement of this phase at 1.0 GPa gives a C-O bond length of 1.168(1) A (Downs and Somayazulu 1998), very close to that of the free molecule. This phase, which is a mineral in the cold polar regions of Mars (Byrne and Ingersoll 2003), can also form at room temperature and pressures above $\sim 0.3 \mathrm{GPa}$. Phase III crystallizes in a Cmca structure. The reported phase II (0.5-2.3 GPa) is less well characterized (Liu 1983), and Downs and Somayazulu (1998) find that phase I is stable in at least part of this pressure range. It has also been reported that a distorted phase IV forms between the stability field of I and III (Olijnyk and Jephcoat 1998). $\mathrm{CO}_{2}$ III was identified by Raman spectroscopy (Hanson 1985; Olijnyk et al. 1988). At pressures >10 GPa carbon dioxide transforms to one of at least three other molecular solids, denoted phases II, III, and IV, as well as a possible phase VII, depending on the temperature (Aoki et al. 1994; Park et al. 2003; Sun et al. 2009; Datchi et al. 2009). However, these relatively low-density forms of crystalline $\mathrm{CO}_{2}$ are not expected to persist at mantle conditions.

The existence of $\mathrm{CO}_{2}$-based framework structures analogous to $\mathrm{SiO}_{2}$ with the coordination of carbon by oxygen increased from three- to four-fold was first shown by Raman studies, which provided direct evidence for a polymeric structure following laser heating at pressures above $\sim 40 \mathrm{GPa}$ and above $2000 \mathrm{~K}$ (Iota et al. 1999). The phase was originally called "quartzlike" based on the close similarity to the vibrational spectra of quartz and named $\mathrm{CO}_{2}-\mathrm{V}$ (Iota et al. 1999). First-principles theory has confirmed the stability of framework structures with tetrahedral carbon; i.e., relative both to the molecular solid and to decomposition to elemental carbon and hydrogen (Serra et al. 1999). Subsequent X-ray diffraction data appeared to be best fit with the tridymite structure (Yoo et al 1999). The stability of the phase has been examined with experiments (Tschauner et al. 2001; Santoro et al. 2006) and theoretical calculations (Holm et al. 2000; Dong, et al. 2000; Bonev et al. 2003; Oganov et al. 2008). An additional possible phase VI with octahedrally-coordinated carbon reported by Iota et al. (2008) has not been confirmed by other experiments or theory. The structures of these phases were until recently under debate. At the same time, it was not possible to rule out that there may be even more stable structures. Evolutionary crystal structure prediction calculations (Oganov et al. 2008) were shown to be consistent with $\beta$-cristobalite as the thermodynamically stable crystal structure (Fig. 8).

The structure of phase V has been recently determined by high-pressure X-ray diffraction measurements (Fig. 9; Datchi et al. 2012; Santoro et al. 2012). Using high-pressure diamond anvil cells combined with high-temperature laser heating, the authors of both studies formed $\mathrm{CO}_{2}-\mathrm{V}$ and probed the crystal structure using synchrotron X-ray diffraction measurements. Through Rietveld analysis methods, both groups determined that $\mathrm{CO}_{2}-\mathrm{V}$ does in fact have the $\beta$-cristobalite structure and is composed of $\mathrm{CO}_{4}$ tetrahedral units. Interestingly, the $\mathrm{CO}_{4}$ units possess $\mathrm{O}-\mathrm{C}-\mathrm{O}$ bond angles that average $109.5^{\circ}$, in stark contrast to molecular carbon dioxide. Structural determination as a function of pressure revealed the bulk modulus of $136 \mathrm{GPa}$, significantly less than the value reported previously (Yoo et al. 1999).

The melting curve of $\mathrm{CO}_{2}$ has been determined to $15 \mathrm{GPa}$ (Giordano et al. 2006; Giordano and Datchi 2007). Quenched samples after laser heating to 2000-3000 K at 28-75 GPa showed that $\mathrm{CO}_{2}$ breaks down to form oxygen and diamond at lower temperature with increasing pressure (Tschauner et al. 2001). Recently, the solid-solid phase transitions, melting behavior, and chemical reactivity of $\mathrm{CO}_{2}$ to these pressures and at temperatures up to $2500 \mathrm{~K}$ using in situ Raman spectroscopy in laser-heated diamond anvil cells were reported by Litasov et al. (2011). Molecular $\mathrm{CO}_{2}$ melts to a molecular fluid up to $33( \pm 2) \mathrm{GPa}$ and $1720( \pm 100) \mathrm{K}$, where it meets a solid-solid phase line to form a triple point (Fig. 10). At higher pressure, non-molecular phase $\mathrm{V}$ does not melt but instead dissociates to carbon and oxygen with a transition line having a negative $P-T$ slope. A comparison with $P-T$ profiles of Earth's mantle indicates that $\mathrm{CO}_{2}-\mathrm{V}$ 
(a)
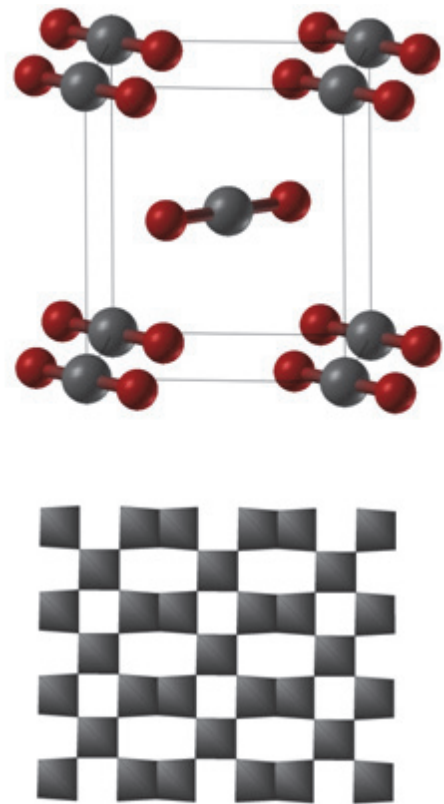

(c)

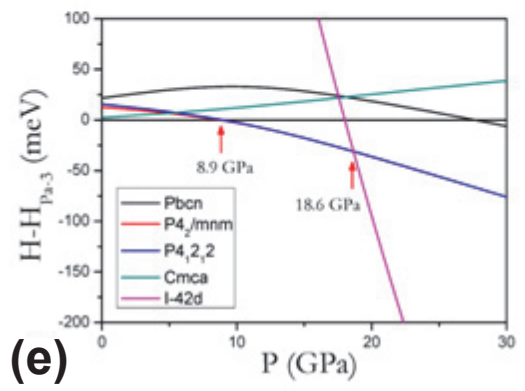

(b)

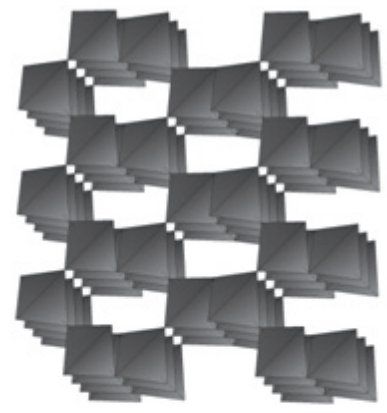

(d)
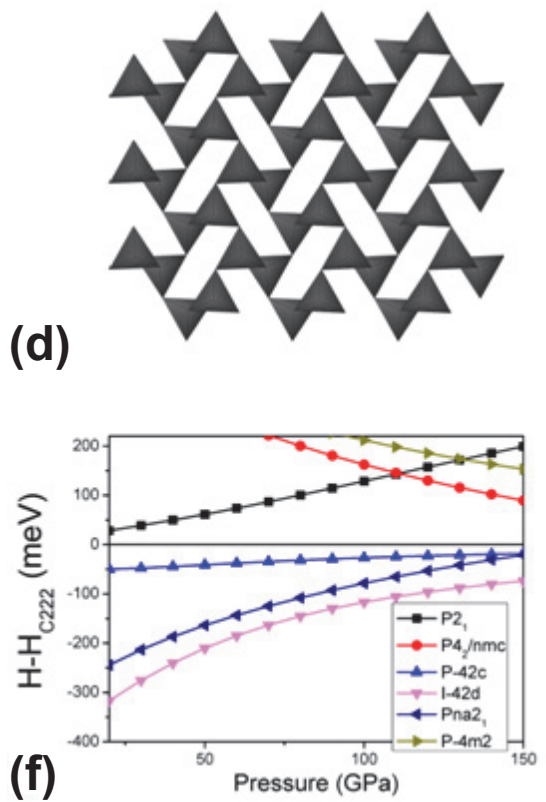

Figure 8. $\mathrm{CO}_{2}$ structures: (a) molecular $\mathrm{P}_{2} / m n m$ structure, stable at lower pressures than polymeric $\mathrm{CO}_{2}-\mathrm{V}$ phase; (b) $\beta$-cristobalite-type structure of $\mathrm{CO}_{2}-\mathrm{V}$ with tetrahedral coordination of carbon atoms; (c) polymeric $C 222_{1}$ structure, (d) metastable polymeric Pna2 $2_{1}$ structure. At the bottom are the calculated enthalpies of candidate structures of $\mathrm{CO}_{2}$ : (e) in the low-pressure region, relative to the molecular Pa3 structure; (f) in the high-pressure region, relative to the non-molecular $C 222$ structure. [Adapted with permission of Elsevier from Oganov et al. (2008) Earth Planet Sci Lett, Vol. 273, p. 38-47, Figs. 2 and 3.]

can be stable near the top of the lower mantle and dissociates at greater depths. Decarbonation reactions of subducted carbonates in the lower mantle would produce diamond and fluid oxygen, which in turn significantly affects redox state, increasing oxygen fugacity by several orders of magnitude. The reaction of free oxygen with lower mantle minerals such as $\mathrm{Mg}$ perovskite could create significant conductivity anomalies (Litasov et al. 2011). Decomposition of $\mathrm{CO}_{2}$ was found to be unlikely by first-principles calculations (Oganov et al. 2008; Boates et al 2012); as the computed enthalpy of decomposition of $\mathrm{CO}_{2}$ is extremely high ( $3.3 \mathrm{eV}$ at 50 $\mathrm{GPa}$ ), discrepancy between experiment and theory that needs to be resolved. Recently, evidence for coesite-structured $\mathrm{CO}_{2}$ has been reported (Sengupta and Yoo 2009). Still higher-pressure 

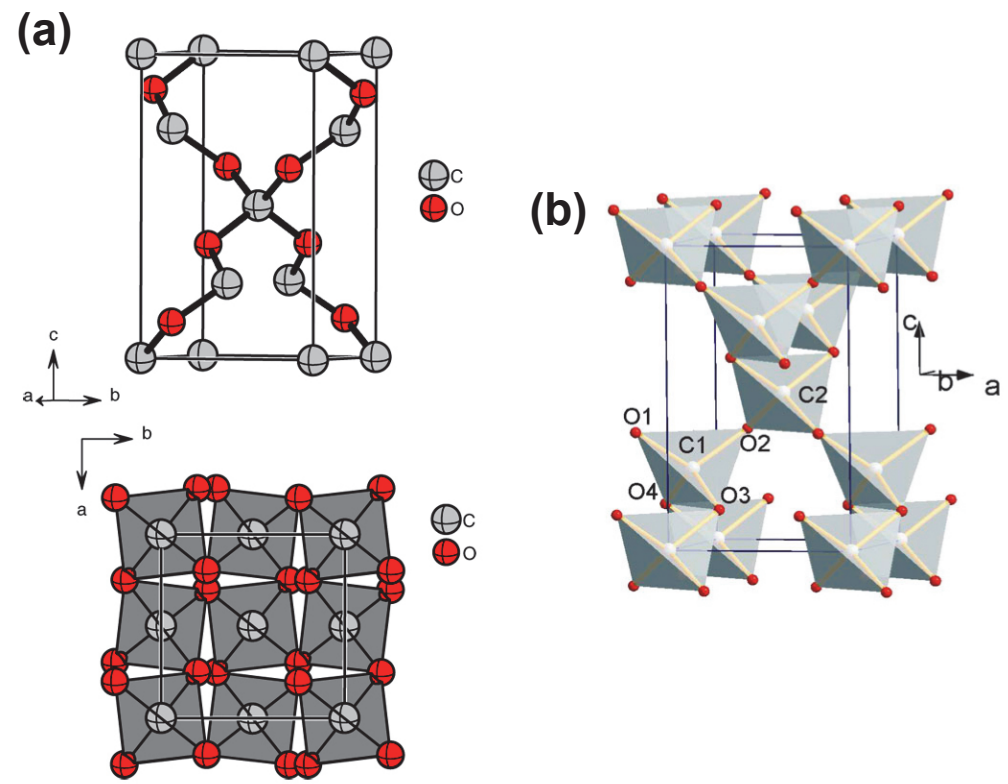

Figure 9. Expermintally determined structure of $\mathrm{CO}_{2}-\mathrm{V}$ at $43 \mathrm{GPa}$ showing partially collapsed arrangement of $\mathrm{CO}_{4}$ tetrahedra. (a) Santoro et al. (2012) [Reproduced with permission of the National Academy of Sciences from Proceedings of the National Academy of Sciences USA, Vol. 109, p. 5176, Fig. 2.]; (b) Datchi et al. (2012) [Reproduced with permission of American Physical Society from Phys Rev Lett, Vol. 108, 125701, Fig. 2(a). http://link.aps.org/doi/10.1103/PhysRevLett.108.125701]

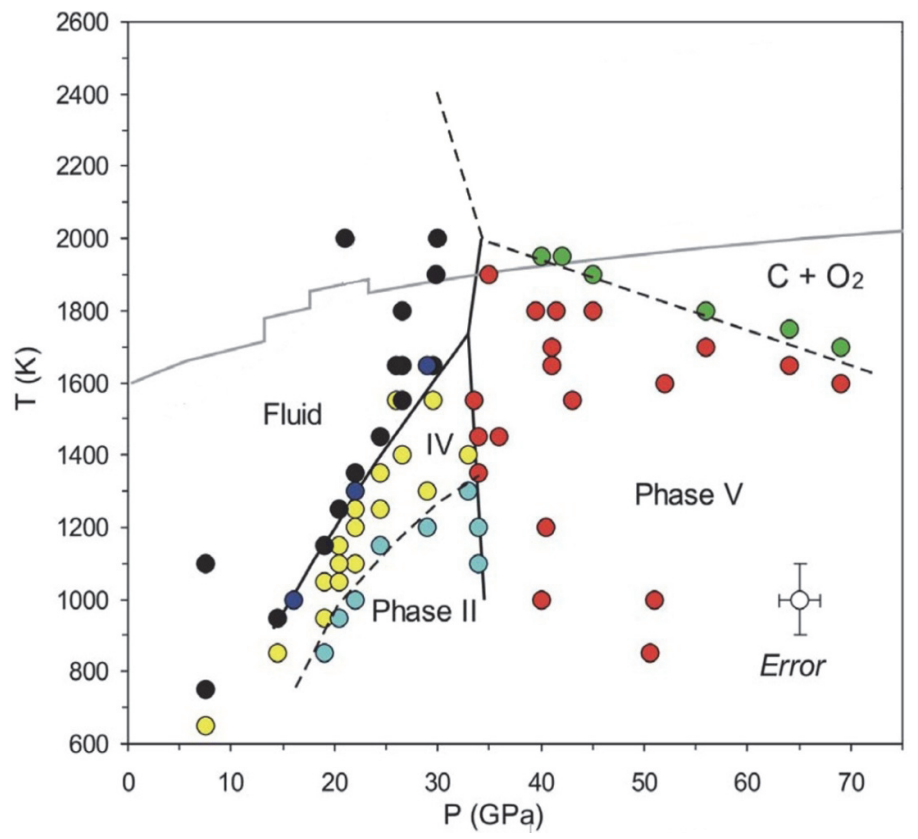

Figure 10. Phase diagram for $\mathrm{CO}_{2}$. The light grey line is an estimated Earth geotherm. [Adapted with permission of Elsevier from Litasov et al. (2011), Earth Planet Sci Lett, Vol. 309, p. 318-323, Fig. 3.] 
structures of $\mathrm{CO}_{2}$ are predicted (Fig. 11), including dissociation at TPa pressures due to the predicted higher density of the elemental assemblage is predicted (Fig. 12).

\section{Other compounds}

Early work on the high-pressure behavior of other binary carbon compounds, in particular formed from simple molecular phases, was reviewed by Hemley and Dera (2000). Recently, structures of carbon monoxide have been investigated theoretically using DFT (Sun et al. 2011). Both three-dimensional frameworks and layered structures were found above $2 \mathrm{GPa}$, although these are metastable. Some of these new structures of $\mathrm{CO}$ (Fig. 13) could be metallic and others might be recoverable to ambient pressure.

The high-pressure behavior of clathrate hydrates, which exist in nature in several forms depending on pressure and temperature and gas composition, are of special interest. Recent high-pressure neutron scattering studies have provided definitive experimental results for testing and refining intermolecular potentials used to describe the hydrophobic interactions in these dense molecular phases (Tulk et al. 2012). These measurements yielded detailed data on the structure of a high-pressure form of methane clathrate hydrate and gave precise information on the number of methane molecules that could fit into the cages of the inclusion compound. The results showed that the correct occupancy for the largest cages in this beautiful structure is three methane molecules. The study provides tests of models for hydrophobic interactions and methane-methane interactions since the high-pressure structure $\mathrm{H}$ clathrate contains cages that are both singly and triply occupied.

Similar types of high-pressure transformations to denser forms can be anticipated for hydrocarbon phases. For example, liquid methane has been observed on Titan's surface and crystalline forms may occur at depth (e.g., Shin et al. 2012). At room temperature and $1.59 \mathrm{GPa}$ methane crystallizes to the low-temperature (methane I) form, in which rotationally disordered $\mathrm{CH}_{4}$ molecules occupy positions of a face-centered cubic (space group $\mathrm{Fm} 3 \mathrm{~m}$ ) lattice (Hazen et al. 1980). The higher-pressure behavior of crystalline methane is complex, with several

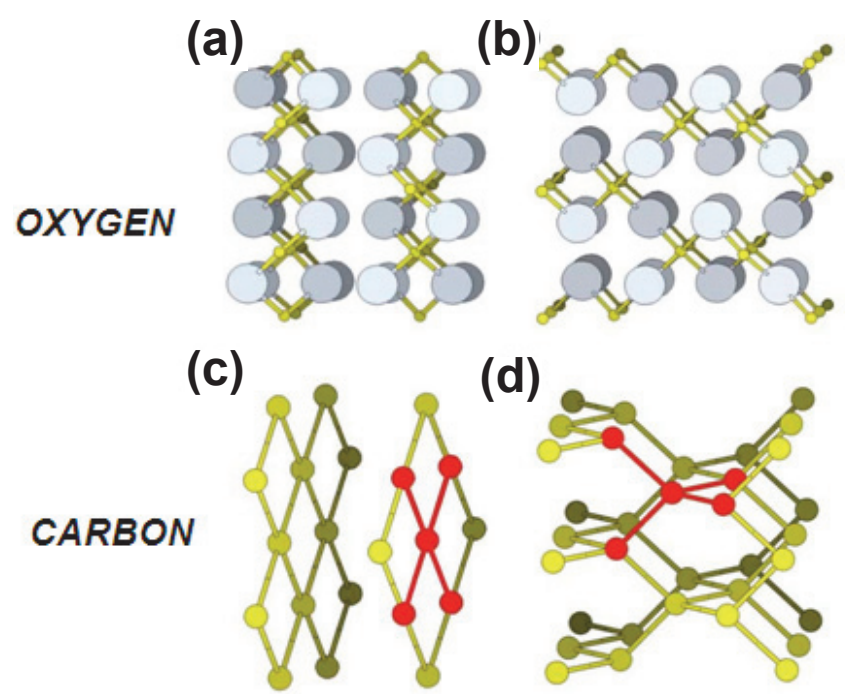

Figure 11. $\beta$-cristabolite and layered structures of $\mathrm{CO}_{2}$ predicted at pressures above $200 \mathrm{GPa}$. (a) and (b) show the $f c c$ oxygen sublatice and (c) and (d) show the carbon sublattice. [Adapted with permssion of the American Physical Society from Lee et al. (2009) Phys Rev B, Vol. 79, 144102, Fig. 4. http://link.aps.org/ doi/10.1103/PhysRevB.79.144102.] 


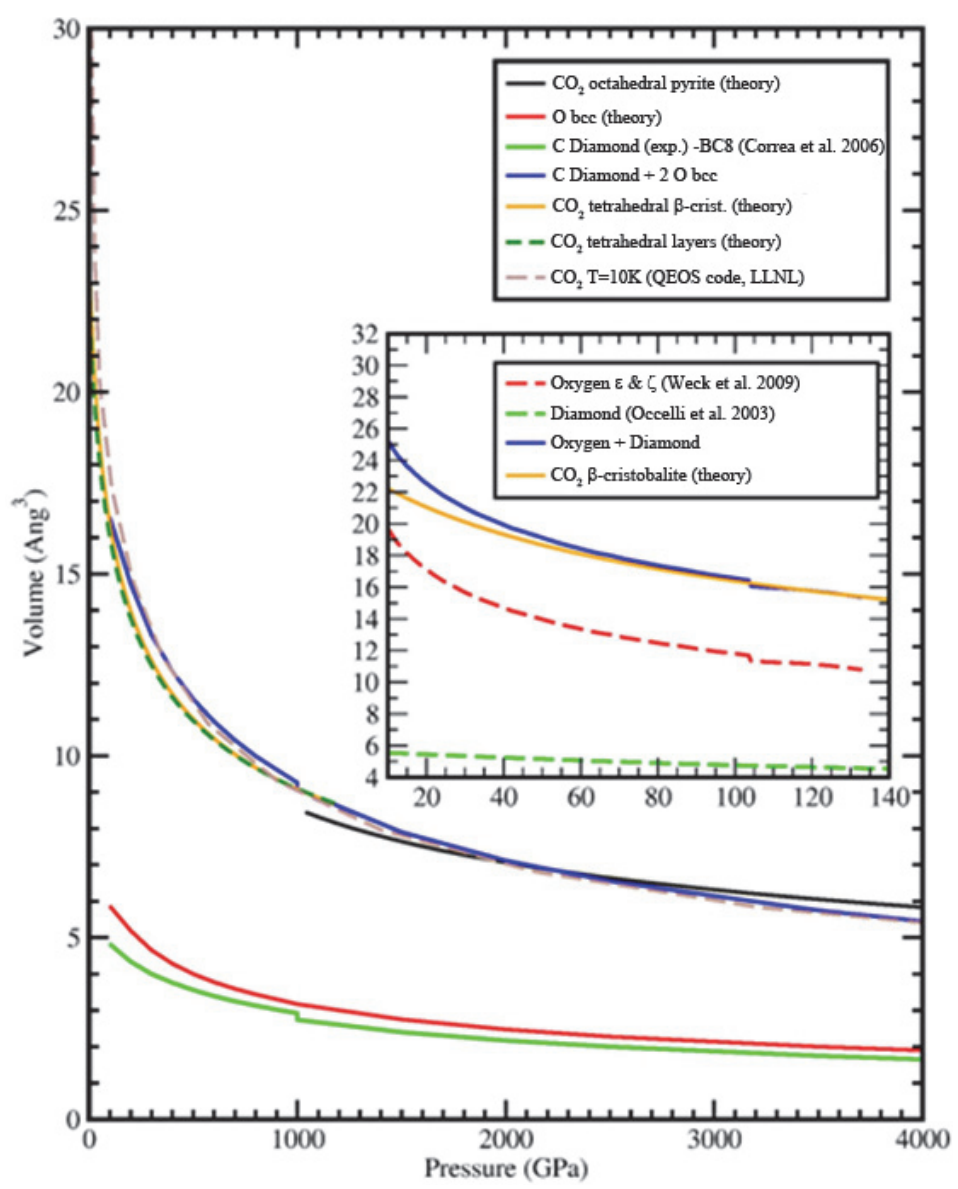

Figure 12. Calculated $P-V$ equations of state of $\mathrm{CO}_{2}, \mathrm{C}$, and $\mathrm{O}$ to ultrahigh (TPa) pressures $(T=0 \mathrm{~K})$. The volume change associated with the calculated breakdown of $\mathrm{CO}_{2}$ to elemental $\mathrm{C}$ and $\mathrm{O}$ is indicated. The lower pressure range is shown in the inset (J. Montoya and R.J. Hemley, unpublished).

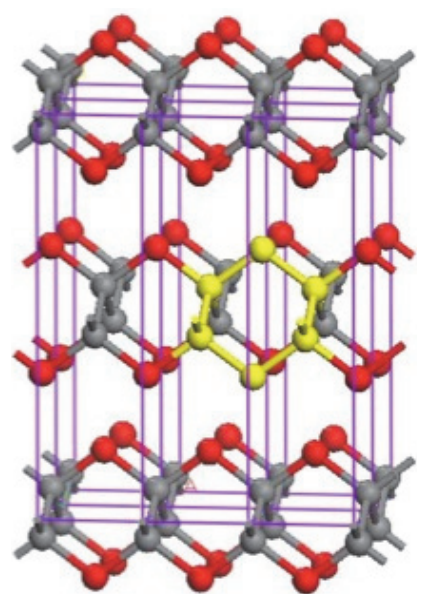

Figure 13. Predicted high-pressure structure of $\mathrm{CO}$ with the $\mathrm{Cmcm}$ layered structure. The grey and red spheres represent $\mathrm{C}$ and $\mathrm{O}$ atoms, respectively, and the yellow spheres identify the six-membered ring in the structure. This represents only one of several high-pressure structures predicted for $\mathrm{CO}$ under pressure (Used with permission of the American Physical Society from Sun et al. (2011) Phys Rev Lett, Vol. 106, 145502, Fig. 2d. http://link. aps.org/doi/10.1103/PhysRevLett.106.145502] 
known phases. Above $5.25 \mathrm{GPa}$ and room temperature solid methane transforms to structures in which the molecules are rotationally locked (Hirai et al. 2008). These studies point to the vast unexplored phase stability of high-pressure molecular hydrocarbons (see, Sephton and Hazen 2013).

\section{CARBONATES}

\section{Behavior of $s p^{2}$ carbonates}

High-pressure phase transitions in rhombohedral carbonates epitomize the challenges of understanding deep carbon mineralogy, because a variety of reversible metastable transitions to slightly denser $s p^{2}$ forms are possible, and these forms are less kinetically inhibited than reconstructive transitions to $s p^{3}$ forms. Calcite provided one of the earliest experimental demonstrations of distinctive metastable high-pressure carbonate phases (Bridgman 1939; Jamieson 1957; Merrill and Bassett 1975). At $\sim 1.5 \mathrm{GPa}$ and $25{ }^{\circ} \mathrm{C}$ calcite transforms displacively to a monoclinic form known as calcite-II with space group $P 2_{1} / c$, with a second reversible transition at $\sim 2.2 \mathrm{GPa}$ to calcite-III (Suito et al. 2001). Catalli and Williams (2005) report yet another transition to a presumably distorted modification of calcite-III at $P \sim 25 \mathrm{GPa}$, which reverts to calcite-III with significant hysteresis on lowering pressure.

Less attention has been paid to the high-pressure polymorphs of other rhombohedral carbonates (Hazen et al. 2013). The high-pressure behavior of ferrous iron and magnesium carbonates, which are likely candidates for deep-Earth carbonates, are of special interest (Biellmann et al. 1993; Isshiki et al. 2004; Panero and Kabbes 2008; Seto et al. 2008). The high-spin (HS) to low-spin (LS) magnetic transition in siderite measured by means of X-ray emission spectroscopy (XES) has been reported to occur at $50 \mathrm{GPa}$ (Mattila et al. 2007). The structure does not change through the spin transition, but there is a discontinuous volume change (Lavina et al. 2010). However, at $10 \mathrm{GPa}$ and $1800 \mathrm{~K}$, siderite breaks down to form a new iron oxide $\mathrm{Fe}_{4} \mathrm{O}_{5}$, isostructural with calcium ferrite, though the residual carbon phase was not identified (Lavina et al. 2011).

Dolomite $\left[\mathrm{CaMg}\left(\mathrm{CO}_{3}\right)_{2}\right]$ is considered to be a major constituent of subducted carbonates (e.g., Zhu and Ogasawara 2002); therefore its phase stability and equation of state at high pressures and temperatures is important to understanding Earth's deep carbon cycle. At pressures below $7 \mathrm{GPa}$ and temperatures between $\sim 500$ and $1000{ }^{\circ} \mathrm{C}$ dolomite is observed to decompose to aragonite plus magnesite (Martinez et al. 1996; Sato and Katsura 2001). As a result, dolomite is normally not considered a potential carrier to transport carbon to Earth's deep interior. However, two higher-pressure phases of dolomite have been documented experimentally. Dolomite-II, which has the calcite-III structure, occurs at pressure $>20 \mathrm{GPa}$ (Santillán et al. 2003). Mao et al. (2011) observed a transition to a significantly denser monoclinic phase called dolomite-III at $41 \mathrm{GPa}$ and $1200{ }^{\circ} \mathrm{C}$, with stability extending to 83 GPa. This study by Mao et al. (2011) provides evidence that the addition of minor amounts of iron can stabilize dolomite in polymorphs that exist at $P$ - $T$ conditions of subducting slabs, thereby providing a mechanism to carry carbonate into the deep mantle. X-ray diffraction/ laser heating techniques were used to study high-pressure and temperature dolomite polymorphs to $83 \mathrm{GPa}$ and $1700 \mathrm{~K}$ of a natural Fe-bearing dolomite from Windham, Vermont with a composition of $\mathrm{Ca}_{0.988} \mathrm{Mg}_{0.918} \mathrm{Fe}_{0.078} \mathrm{Mn}_{0.016}\left(\mathrm{CO}_{3}\right)_{2}$. They observed two distinct phase transformations: 1) to dolomite-II at $\sim 17 \mathrm{GPa}$ and $300 \mathrm{~K}$, and 2) to a new monoclinic phase (dolomite-III) between 36 and $83 \mathrm{GPa}$. Both high-pressure polymorphs were stable up to 1500 $\mathrm{K}$, indicating that the addition of minor Fe stabilizes dolomite under the conditions akin to the deep mantle. Thus, Fe-dolomite may provide a means for delivering carbon to Earth's deep interior, though additional experiments are required to determine the structure of dolomiteIII, examine the potential effects of Fe substitution on the phase transitions, and determine 
the redox properties of Fe-bearing carbonate in Earth's mantle. A recent experimental study examined the high-pressure vibrational and elastic properties of iron-bearing magnesite across the spin transition. Distinctive changes in the unit cell volumes and vibrational properties are indicative of a high-spin to low-spin transition at $40 \mathrm{GPa}$. The spin transition enhances the stability of the carbonate phase (Lin et al 2012).

The orthorhombic aragonite group minerals (Hazen et al. 2013) have received less study at high pressure. Holl et al. (2000) studied witherite to $8 \mathrm{GPa}$ and found that it undergoes a displacive phase transition at approximately $7 \mathrm{GPa}$. The topology of the structure did not change, but the $\mathrm{CO}_{3}$ groups shifted into the same plane as the Ba atoms, changing the symmetry to hexagonal.

\section{High-pressure $s p^{3}$ carbonates}

Given the behavior of other carbon-bearing systems at very high pressure, it seems likely that the $s p^{2}$ carbonates with trigonally coordinated carbon will transform to $s p^{3}$ polymorphs with tetrahedrally-coordinated carbon. At $\sim 40 \mathrm{GPa}$, Ono et al. (2005) found a phase transition from aragonite to another phase, which was subsequently solved using the USPEX method and verified experimentally (Fig. 14; Oganov et al. 2006; Ono et al. 2007). The structure (orthorhombic, space group Pmmn) was called post-aragonite; it still has carbon in the $s p^{2}$-state $\left(\mathrm{CO}_{3}\right.$-anions), and is characterized by 12 -fold coordination of $\mathrm{Ca}$ atoms and joint hexagonal

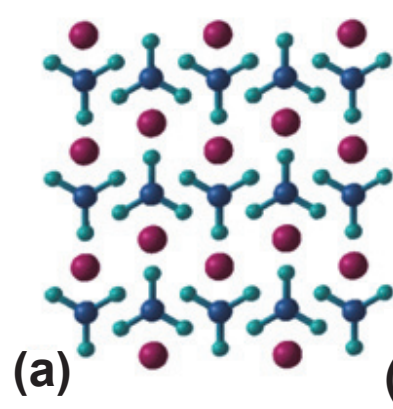

(b)
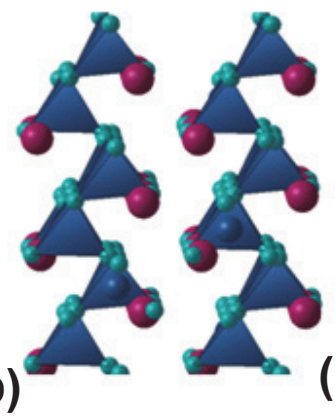

(c)
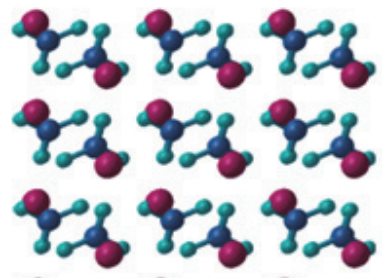

)

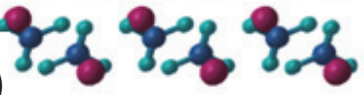

(d)
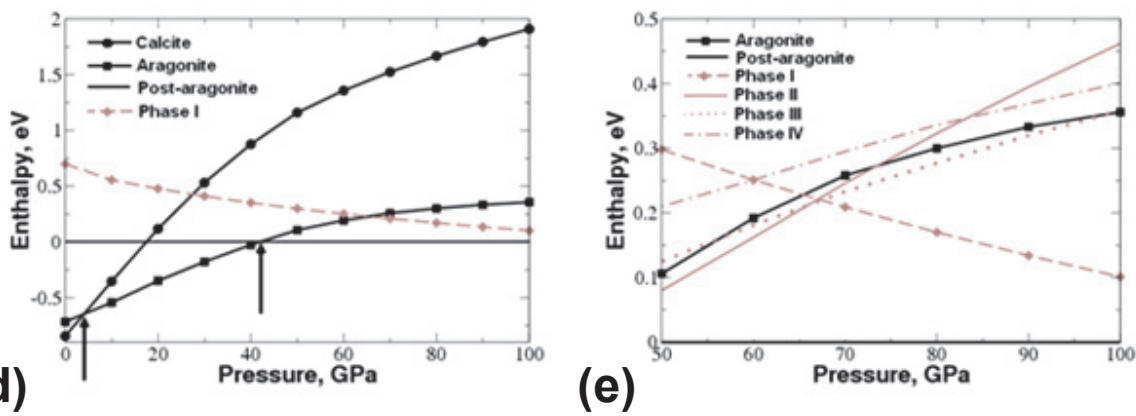

Figure 14. Predicted structures of high-pressure polymorphs of $\mathrm{CaCO}_{3}$ : (a) post-aragonite (stable at 42 to $137 \mathrm{GPa}$ ); (b) $C 222_{1}$ phase (stable at $>137 \mathrm{GPa}$ ); (c) $P \overline{1}$ phase, probably stable in a narrow pressure range of a few GPa between aragonite and post-aragonite. (d) and (e) Enthalpies of candidate structures of $\mathrm{CaCO}_{3}$ as a function of pressure, in $\mathrm{eV}$ per formula unit, relative to post-aragonite. [Adapted with permission of Elsevier from Oganov et al. (2006) Earth Planet Sci Lett, Vol. 241, p. 95-103, Figs. 1c-e, Fig. 3.] 
close packing of oxygen and calcium atoms. At pressures above $137 \mathrm{GPa}$, a new structure was predicted using USPEX (Oganov et al. 2006), and once again the predicted structure matched the experimental X-ray diffraction patterns obtained at $P>130 \mathrm{GPa}$ (Ono et al. 2007). The structure (space group $C 222_{1}$ ) features chains of carbonate tetrahedra similar to silicate tetrahedral chains in pyroxenes. However, unlike pyroxenes, the $C 222_{1}$ structure has large cations in one position (rather than two in pyroxenes). The presence of tetrahedral carbonate ions (with $s p^{3}$ hybridization) marks a dramatic shift in the chemistry of carbonates. Note that both post-aragonite and the $C 222_{1}$ structures belong to new structure-types, which could not have been found by analogy with any known structures. Another new structure with $P \overline{1}$ symmetry was found by (Oganov et al. 2006) as metastable and energetically closely competitive with aragonite in a wide pressure range. It is predicted to be stable in a narrow (a few GPa) pressure interval around $42 \mathrm{GPa}$, between aragonite and post-aragonite. A phase with this structure was recently documented in experiments of Merlini et al. (2012).

Experiments demonstrate that magnesite is stable at least up to $~ 80 \mathrm{GPa}$ (Fiquet et al. 2002) and transforms to a new phase above $100 \mathrm{GPa}$ (Isshiki et al. 2004). Systematic search through databases of known crystal structures, combined with energy minimization, indicated that a pyroxene structure (space group $C 2 / c$ ) becomes energetically more favorable than magnesite above $100 \mathrm{GPa}$ (Skorodumova et al. 2005), but Oganov et al. (2006) found that the C222 structure (stable for $\mathrm{CaCO}_{3}$ ) is preferable to the $C 2 / c$ pyroxene structure. USPEX simulations at $110 \mathrm{GPa}$ and $150 \mathrm{GPa}$ found a large number of low-enthalpy structures that are competitive in a wide pressure range and are more favorable than previously known structures (Oganov et al. 2008). Magnesite was found to be stable up to $82 \mathrm{GPa}$, whereas at higher pressures there are two phases with similar structures containing three-membered rings $\left(\mathrm{C}_{3} \mathrm{O}_{9}\right)^{6-}$ made of carbonate tetrahedra (Fig. 15) and $\mathrm{Mg}$ atoms in eight- and ten-fold coordination.

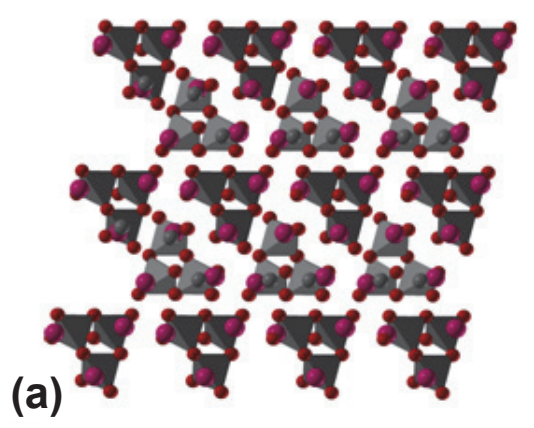

(b)
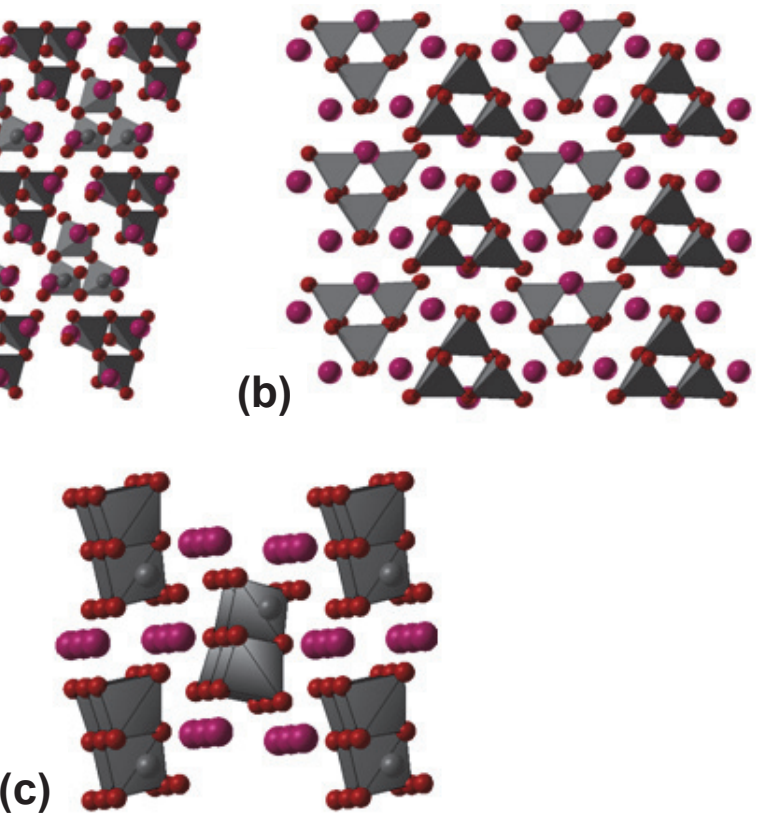

Figure 15. Predicted structures of stable high-pressure phases of $\mathrm{MgCO}_{3}$ : (a) post-magnesite phase II; (b) phase III; (c) Pna2 ${ }_{1}-20$ structure. [Adapted with permission of Elsevier from Oganov et al. (2008) Earth Planet Sci Lett, Vol. 273, p. 38-47, Fig. 5.] 
These unusual structures were confirmed experimentally in a recent X-ray diffraction study by Boulard et al. (2011), who found that the $\mathrm{Mg}-\mathrm{Fe}$ carbon-bearing compound can form at conditions corresponding to depths greater than $1,800 \mathrm{~km}$ (Fig. 16). Its structure, based on three-membered rings of corner-sharing $\left(\mathrm{CO}_{4}\right)^{4-}$ tetrahedra, closely agrees with the earlier predictions (Oganov et al. 2008). This polymorph of carbonates concentrates $\mathrm{Fe}^{(\mathrm{III})}$ as a result of intracrystalline reaction between $\mathrm{Fe}^{(\mathrm{II})}$ and $\mathrm{CO}_{3}{ }^{2-}$ groups schematically written as $4 \mathrm{FeO}+\mathrm{CO}_{2} \rightarrow$ $2 \mathrm{Fe}_{2} \mathrm{O}_{3}+\mathrm{C}$. This oxidation-reduction reaction results in an assemblage consisting of the new high-pressure phase, magnetite, and diamond. Above $160 \mathrm{GPa}$ (Oganov et al. 2008), simulations predict a structure with space group $P n a 2_{1}$ containing chains of corner-sharing carbonate tetrahedra to be stable.

The presence of tetrahedral carbonate-ions at very high pressures invites an analogy with silicates, but the analogy is limited. In silicates,

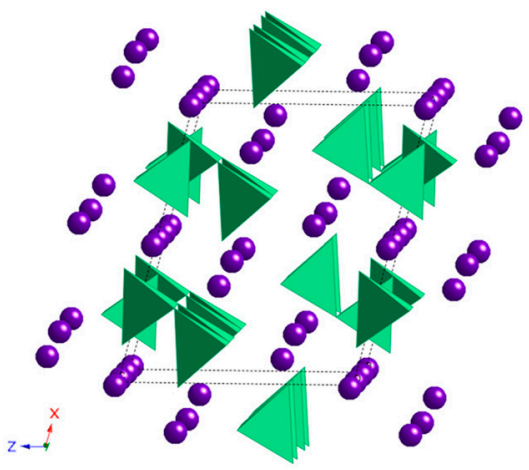

Figure 16. Experimentally determined structure of the high-pressure ferromagnesium carbonate phase with space group $P 21 / c$. $\left(\mathrm{CO}_{4}\right)^{4-}$ tetrahedral appear in green and magnesium atoms are shown as violet spheres. [Reproduced with permission of the National Academy of Sciences from Boulard et al. (2011) Proceedings of the National Academy of Sciences USA, Vol. 108, p. 5184-5187, Fig. 4.] the inter-tetrahedral angle $\mathrm{Si}-\mathrm{O}-\mathrm{Si}$ is extremely flexible (Belov 1961), which is one of the reasons for the enormous diversity of silicate structure types. Figure 17 shows the variation of the energy as a function of the Si-O-Si angle in the model $\mathrm{H}_{6} \mathrm{Si}_{2} \mathrm{O}_{7}$ molecule (Lasaga and Gibbs 1987). One can see only a shallow minimum at $\mathrm{Si}-\mathrm{O}-\mathrm{Si} \approx 135^{\circ}$, but a deep minimum at $\mathrm{C}$ $\mathrm{O}-\mathrm{C} \approx 124^{\circ}$ with steep energy variations for $\mathrm{H}_{6} \mathrm{C}_{2} \mathrm{O}_{6}$. This difference suggests a much more limited structural variety of tetrahedral carbonates, compared to silicates. The C-O-C angles in the tetrahedral structures of $\mathrm{CO}_{2}, \mathrm{CaCO}_{3}$, and $\mathrm{MgCO}_{3}$ are in the relatively narrow range from $115^{\circ}$ to $125^{\circ}$ at atmospheric pressure and decrease to $112^{\circ}$ to $115^{\circ}$ at $100 \mathrm{GPa}$. The differences between silicates and tetrahedral carbonates can also be seen from the large differences in the high-pressure structures of $\mathrm{CO}_{2}, \mathrm{CaCO}_{3}$, and $\mathrm{MgCO}_{3}$ and the stable structures of $\mathrm{SiO}_{2}, \mathrm{CaSiO}_{3}$, and $\mathrm{MgSiO}_{3}$.

The fundamental change of carbonate chemistry from $s p^{2}$ (triangular carbonate ions) to $s p^{3}$ (tetrahedral carbonate ions) has important consequences for the viscosity of carbonate melts, which at high pressures (presumably above $~ 80$ to $130 \mathrm{GPa}$ ) is expected to be rather high (in contrast to very low viscosity of liquid carbonates at low pressures; Jones et al. 2013). This prediction remains to be confirmed experimentally.

\section{Silicate carbonates}

Under ambient conditions, $\mathrm{CO}_{2}$ and $\mathrm{SiO}_{2}$ are thermodynamically stable and do not react. Therefore, a natural question is whether or not compounds between $\mathrm{CO}_{2}$ and $\mathrm{SiO}_{2}$ are even possible under any conditions, and how they might relate to recently identified silica clathrate in carbonatite (melanophlogite: Beard et al. 2013). A recent study has reported the discovery that a silicon carbonate phase can form from carbon dioxide and silica under pressure (Santoro et al. 2011). In this work, dense carbon dioxide fills the micro-pores of silicalite, a pure $\mathrm{SiO}_{2}$ zeolitic material, at high pressure. All the $\mathrm{SiO}_{4}$ tetrahedra are on the surface of the micropores and consequently in contact with the $\mathrm{CO}_{2}$. The large effective interaction area between the two materials greatly favors the chemical reaction between them. This silicon carbonate phase is obtained when the system is compressed to $18-20 \mathrm{GPa}$ and heated at 600-700 K. The material can be temperature quenched and was characterized by optical spectroscopy and synchrotron 

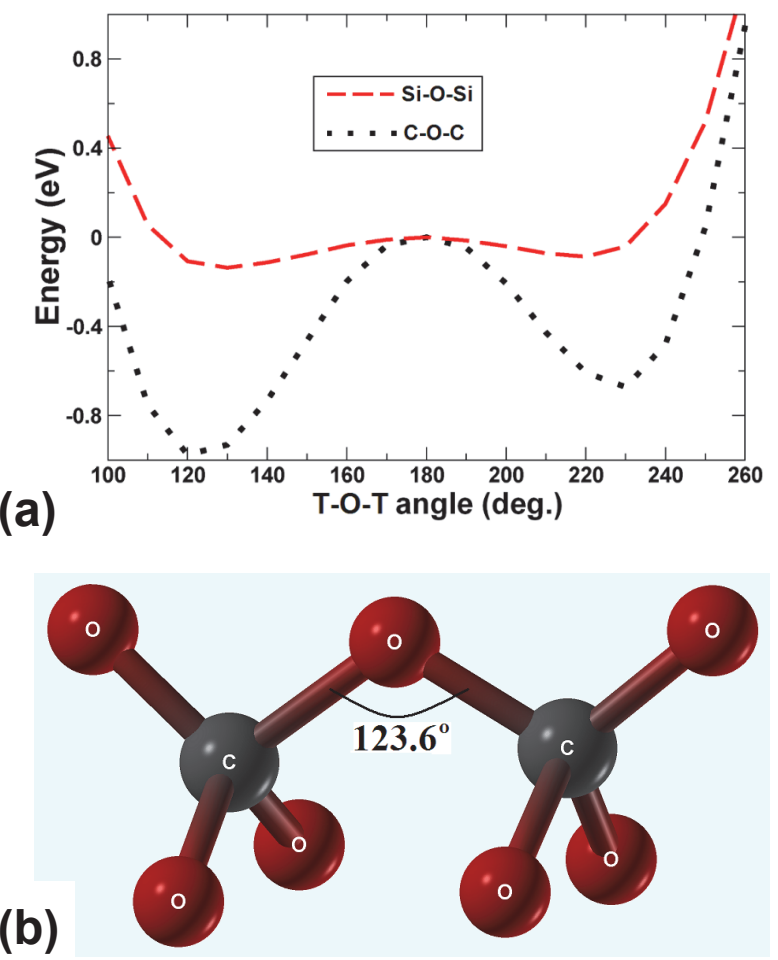

Figure 17. (a) Energy variation as a function of the T-O-T angle (red dashed line $=\mathrm{Si}$; black dotted line $=\mathrm{C}$ ). Calculations were performed on $\mathrm{H}_{6} \mathrm{~T}_{2} \mathrm{O}_{7}$ molecules; at each angle all T-O distances and O-T-O valence angles were optimized. (b) The minimum energy configuration of $\mathrm{C}_{2} \mathrm{O}_{7}$ has a $123.6^{\circ} \mathrm{C}-\mathrm{O}-\mathrm{C}$ angle. [Adapted with permission of Elsevier from Oganov et al. (2008) Earth Planet Sci Lett, Vol. 273, p. 38-47, Fig. 7.]

X-ray diffraction (Fig. 18). The structure of this new compound reflects that of the original silicalite crystal, although it is affected by stoichiometric and spatial disorder.

High-pressure silicate-carbonates with 4-coordinated carbon and 6-coordinated silicon represent an as yet unexplored crystal chemical possibility. More than 50 low-pressure silicatecarbonates with 3-coordinated carbon and 4-coordinated silicon are known, most notably the Ca-Si-carbonates spurrite $\left[\mathrm{Ca}_{5}\left(\mathrm{SiO}_{4}\right)_{2}\left(\mathrm{CO}_{3}\right)\right]$ and tilleyite $\left[\mathrm{Ca}_{5}\left(\mathrm{Si}_{2} \mathrm{O}_{7}\right)\left(\mathrm{CO}_{3}\right)_{2}\right]$. Some of these unusual crystal structures, which incorporate both planar $\mathrm{CO}_{3}$ and tetrahedral $\mathrm{SiO}_{4}$ units, may represent plausible structure topologies for high-pressure calcium carbonates with carbon in mixed 3- and 4-coordination.

Alternatively, polyhedral packing arrangements for tetravalent cations in both tetrahedral and octahedral coordination are well established. For example, $\left(\mathrm{GeO}_{6}\right)$ octahedra and $\left(\mathrm{SiO}_{4}\right)$ tetrahedra combine in the synthetic phases $\mathrm{Ca}_{2} \mathrm{Ge}_{2} \mathrm{Si}_{5} \mathrm{O}_{16}$ and $\mathrm{BaGeSi}_{3} \mathrm{O}_{6}$ (Robbins et al. 1968; Smolin 1969; Nevskii et al. 1979), while the rare mineral bartelkeite $\left[\mathrm{PbFeGe} \mathrm{VI}^{\mathrm{VI}}\left(\mathrm{Ge}^{\mathrm{IV}}{ }_{2} \mathrm{O}_{7}\right)(\mathrm{OH})_{2}\right.$. $\mathrm{H}_{2} \mathrm{O}$ ] incorporates both $\mathrm{GeO}_{4}$ and $\mathrm{GeO}_{6}$ polyhedra (Origlieri et al. 2012). These structure types, therefore, are possible isomorphs for silicate-carbonates at mantle pressures. In addition, Hazen et al. (1996) describe a related group of unusual high-pressure framework silicates with mixed 4- and 6-coordinated silicon (Fig. 19) with the general formula:

$$
\left[\left(A^{1+}{ }_{4-2 x} B^{2+}{ }_{x}\right) \mathrm{Si}^{\mathrm{VI}}{ }_{m}\left(\mathrm{Si}^{\mathrm{IV}}{ }_{n} \mathrm{O}_{2(m+n)+2}\right]\right.
$$

where $A$ and $B$ are monovalent and divalent cations, respectively, in 8 or greater coordination. All of these layered structures, including the benitoite form of $\mathrm{BaSi}_{4} \mathrm{O}_{9}$ and the wadeite form of $\mathrm{K}_{2} \mathrm{Si}_{4} \mathrm{O}_{9}$ (Swanson and Prewitt 1983; Finger et al. 1995), possess densities intermediate between those of purely 4- or 6-coordinated phases, and thus must represent a transitional pressure 


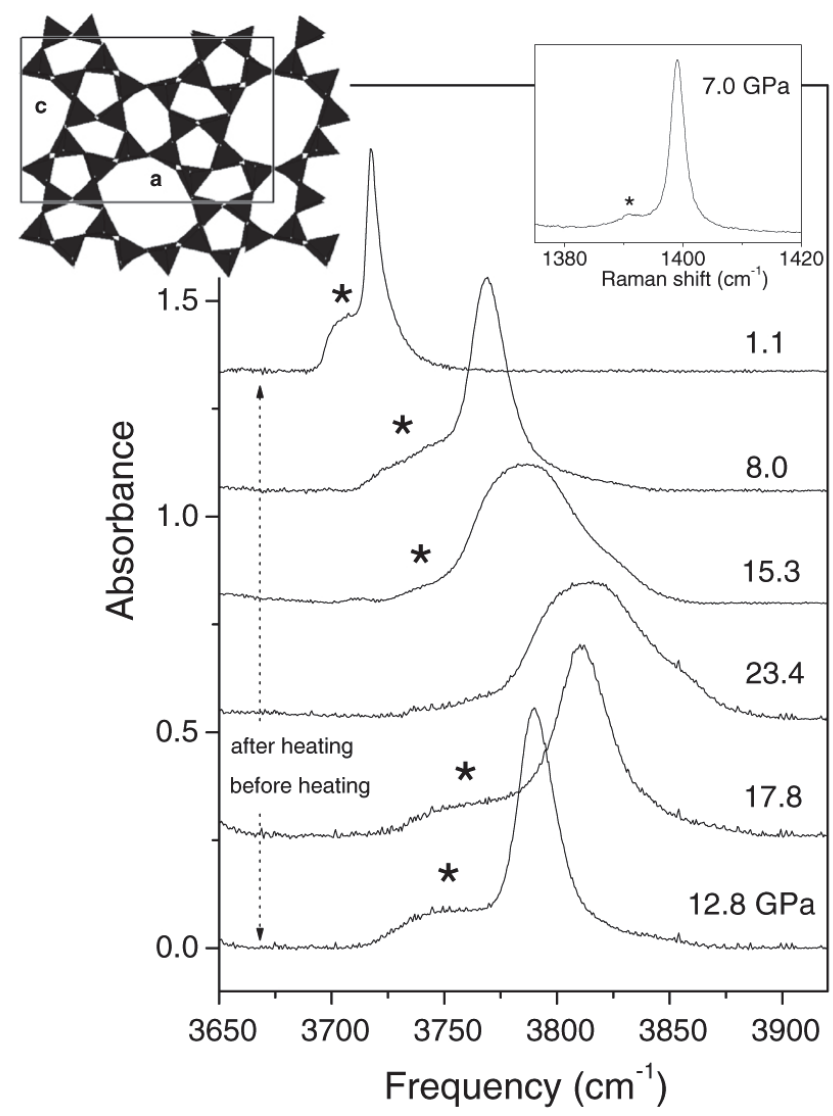

Figure 18. Infrared and Raman spectra (right insert) of mixed silicate and $\mathrm{CO}_{2}$ showing the formation of the high pressure silicon carbonate phase. A schematic representation of the original silicate structure is shown in the left inset. [Reproduced with permission of the National Academy of Sciences from Santoro et al. (2011) Proceedings of the National Academy of Sciences USA, Vol. 108, p. 7689-7692, Fig. 1.]

range. Therefore, with the caveat that $\mathrm{O}-\mathrm{C}-\mathrm{O}$ angles are more restricted than $\mathrm{O}-\mathrm{Si}-\mathrm{O}$ angles (see above), a variety of plausible deep-Earth silicate-carbonate structures, including alkali and alkaline earth silicate-carbonate phases, should not be overlooked. At pressures significantly greater than those of Earth's lower mantle it is likely that silicon adopts a coordination greater than six; possible mixed carbon-silicate phases in this regime remains to be explored. These phases could be important components of carbon-rich super-Earths.

Finally, the nature of carbonates and silicate-carbonates at more extreme conditions, including those reached on dynamic compression, represents an unexplored area for future research. Transient shock pressures generated in bolide impacts exceed the duration of laboratory shock synthesis by orders of magnitude and, despite potential kinetic effects (DeCarli et al. 2002b), offer distinct potential for understanding the high-pressure behavior of carbon mineralogy. Combinations of natural observations, experiments, and modeling provide an important framework for understanding high-pressure phase equilibria in mixed carbonsilicate and simple carbonate systems over a very wide temperature interval (Martinez et al. 1998; Jones et al. 2000). 

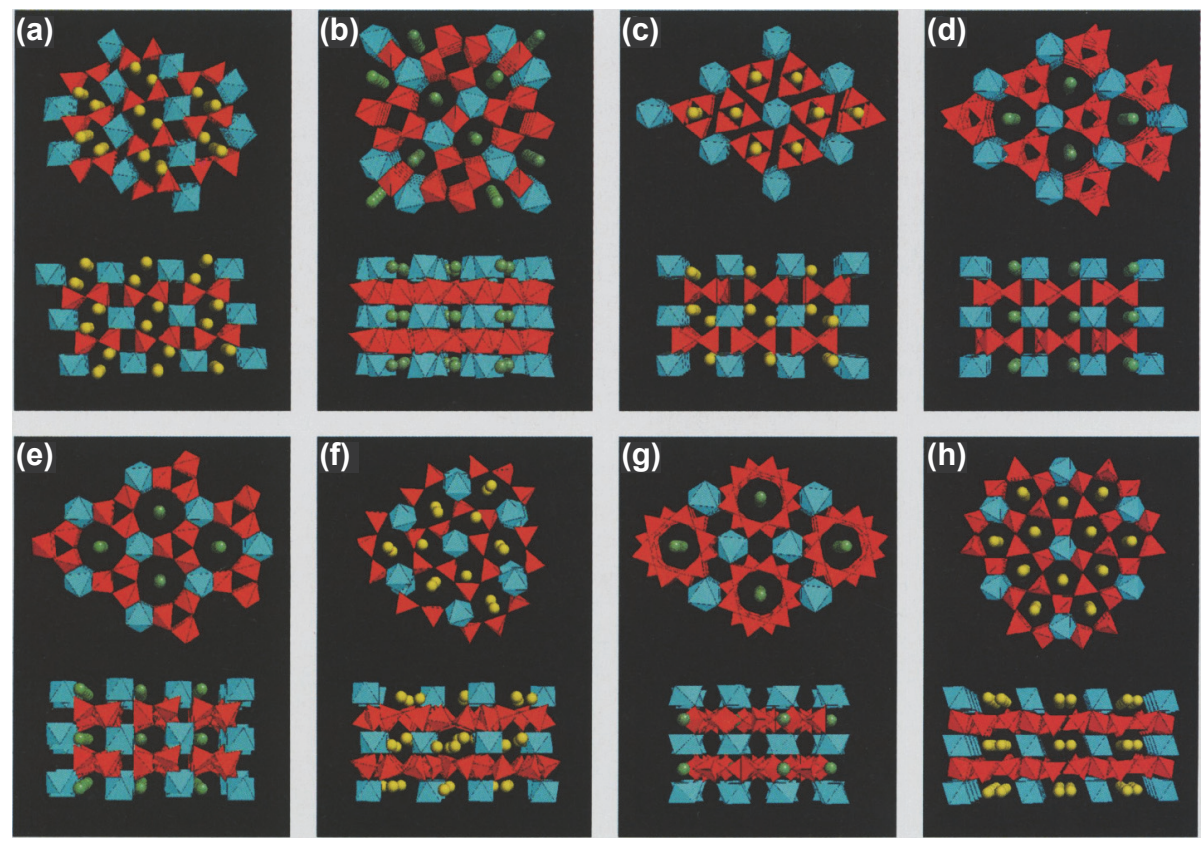

Figure 19. Observed and predicted framework silicates with $\mathrm{SiO}_{4}$ tetrahedra (red), $\mathrm{SiO}_{6}$ octahedra (blue), alkali cations (yellow spheres), and alkaline earth cations (green spheres) might represent carbonate-silicate structures at elevated temperature and pressure. Structures are shown in views parallel and perpendicular to layers of tetrahedral groups. (a) sodium silicate, $\mathrm{Na}_{4} \mathrm{Si}_{2}{ }^{\mathrm{VI}} \mathrm{Si}_{4}{ }^{\mathrm{IV}} \mathrm{O}_{14}$; (b) predicted calcium germanate-type, $\mathrm{Ca}_{2} \mathrm{Si}_{2}{ }^{\mathrm{VI}} \mathrm{Si}_{5}{ }^{\mathrm{IV}} \mathrm{O}_{16}$; (c) wadeite-type $\mathrm{K}_{4} \mathrm{Si}_{2}{ }^{\mathrm{VI}} \mathrm{Si}_{6}{ }^{\mathrm{IV}} \mathrm{O}_{18}$; (d) benitoite-type $\mathrm{Ba}_{2} \mathrm{Si}_{2}{ }^{\mathrm{VI}} \mathrm{Si}_{6}{ }^{\mathrm{IV}} \mathrm{O}_{18}$; (e) barium germanatetype $\mathrm{Ba}_{2} \mathrm{Si}_{2}{ }^{\mathrm{VI}} \mathrm{Si}_{6}{ }^{\mathrm{IV}} \mathrm{O}_{18}$; (f) sodium silicate, $\mathrm{Na}_{4} \mathrm{Si}_{2}{ }^{\mathrm{VI}} \mathrm{Si}_{6}{ }^{\mathrm{IV}} \mathrm{O}_{18}$; (g) predicted beryl-type $\mathrm{Ba}_{2} \mathrm{Si}_{2}{ }^{\mathrm{VI}} \mathrm{Si}_{6}{ }^{\mathrm{IV}} \mathrm{O}_{18}$; (h) sodium-calcium silicate, $\mathrm{Na}_{1.8} \mathrm{Ca}_{1.1} \mathrm{Si}^{\mathrm{VI}} \mathrm{Si}_{5}{ }^{\mathrm{IV}} \mathrm{O}_{14}$. [Reproduced with permission of The American Association for the Advancement of Science from Hazen et al. (1996) Science, Vol. 272, p. 1769-1770, Fig. 1.]

\section{CONCLUSIONS}

This survey of carbon mineralogy outlines much that is known regarding varied possible C-bearing mineral phases in deep planetary interiors. With the exception of the diamond polymorph of carbon and rare occurrences of Si and Fe carbides (Hazen et al. 2013), deep carbon phases have not been well documented, and with few notable exceptions, their high-pressure stability limits are still poorly understood. Furthermore, although the measured solubility of carbon in nominally acarbonaceous upper mantle silicates is extremely low (Keppler et al. 2003), the potential for carbon solid solution in lower mantle and core phases, including oxides, silicates, sulfides, and silicate melts, is not well constrained (Ni and Keppler 2013). Thus, while documented inventories of Earth's carbon represent only $\sim 0.07 \mathrm{wt} \%$, hidden reservoirs may represent in excess of $1.5 \%$ (Mason 1979; Kerridge 1985; Javoy 1997). This situation is analogous to our understanding of the deep hydrogen cycle 30 years ago (Smyth 2006; Smyth and Jacobsen 2006). Future high-pressure studies might consider the significant potential for storage and distribution of trace elements in $\mathrm{C}$ phases, including $\mathrm{N}$, light elements, and especially noble gases, whose association with deep carbon is implied from volcanic degassing and from cosmochemistry (see Marty et al. 2013). We should also examine whether stability of new high-pressure C-bearing phases may influence isotopic fractionation at high-pressure conditions (Mikhail et al. 2011), which has enormous implications for reservoirs, fluxes, and geodynamic processes from the core to the atmosphere. 
A great deal has been learned recently from both high-pressure experiments and computational theory. Recent advances point to the likelihood of novel $s p^{3}$ phases with tetrahedrally-coordinated carbon, including topologies that differ from those of silicate minerals. High-pressure carbonates and carbonate-silicates will continue to be of special interest in modeling the extent and distribution of mantle carbon and elucidating the deep carbon cycle. High-pressure studies of carbon-bearing molecular phases also hold great promise for discovering novel phases with unusual properties. We thus anticipate that the next decade will see rapid and fundamental advances in the understanding of the mineralogy of carbon at extreme conditions.

\section{ACKNOWLEDGMENTS}

We thank J. Armstrong, R. E. Cohen, R. T. Downs, C. Schiffries, and D. A. Sverjensky for invaluable discussions and suggestions during the preparation of this manuscript. The authors gratefully acknowledge support from the Deep Carbon Observatory, the Alfred P. Sloan Foundation, the Carnegie Institution of Washington, the National Science Foundation, DARPA, and NASA's Astrobiology Institute for support of this study.

\section{REFERENCES}

Adams L (1921) The compressibility of diamond. J Wash Acad Sci 11:45-50

Ahrens TJ (1982) Constraints on core composition from shockwave data. Philos Trans R Soc London A306:3747

Amsler M, Flores-Livas JA, Lehtovaara L, Balima F, Ghasemi SA, Machon D, Pailhes S, Willand A, Caliste D, Botti S, San Miguel A, Goedecker S, Marques MAL (2012) Crystal structure of cold compressed graphite. Phys Rev Lett 108:065501

Aoki K, Yamawaki H, Sakashita M, Gotoh Y, Takemura K (1994) Crystal structure of the high-pressure phase of solid $\mathrm{CO}_{2}$. Science 263:356-358

Arapan S, Souza de Almeida J, Ahuja R (2007) Formation of $\mathrm{sp}^{3}$ hybridized bonds and stability of $\mathrm{CaCO}_{3}$ at very high pressure. Phys Rev Lett 98:268501

Aryasetiawan F, Gunnarson O (1998) The GW methods. Rep Prog Phys 61:237

Aust RB, Drickamer HG (1963) Carbon: A new crystalline phase. Science 140:817-819

Baughman R, Liu A, Cui C, Schields P (1997) A carbon phase that graphitizes at room temperature. Synth Met $86: 2371-2374$

Bazhanova ZG, Oganov AR, Gianola O (2012) Fe-C-H system at pressures of the Earth's inner core. Phys Usp 55:489-497

Beard AD, Howard K, Carmody L, Jones AP (2013) Melanophlogite pseudomorphing combeite: A new occurrence from the 2006 eruption of Oldoinyo Lengai, Tanzania. Submitted to American Mineralogist.

Belov NV (1961) Crystal Chemistry of Silicates with Large Cations. Russian Academy of Sciences Press, Moscow

Berman R, Simon F (1955) On the graphite-diamond equilibrium. Z Elektrochem 59:333

Biellmann C, Gillet P, Guyot F, Peyronneau J, Reynard B (1993) Experimental evidence or carbonate stability in Earth's lower mantle. Earth Planet Sci Lett 118:31-41

Birch F (1964) Density and composition of the mantle and the core. J Geophys Res 69:4377-4388

Boates B, Teweldeberhan AM, Bonev SA (2012) Stability of dense liquid carbon dioxide. Proc Natl Acad Sci 109:14808-14812

Bonev SA, Gygi F, Ogitsu T, Galli G (2003) High-pressure molecular phases of solid carbon dioxide. Phys Rev Lett 91:065501

Boulard E, Gloter A, Corgne A, Antonangeli D, Auzende A, Perrillat J, Fuyot F, Fiquet G (2011) New host for carbon in the deep Earth, Proc Natl Acad Sci USA 108:5184-5187

Boulfelfel SE, Oganov AR, Leoni S (2012) Understanding the nature of "superhard graphite". Sci Rep 2:471

Brazhkin VV, Lyapin AG, Hemley RJ (2002) Harder than diamond: dreams and reality. Philos Mag A 82:231253

Bridgman PW (1939) The high-pressure behavior of miscellaneous minerals. Am J Sci 237:7-18

Bulanova G, Walter M, Smith CB, Kohn SC, Armstrong LS, Blundy J, Gobbo L (2010) Mineral inclusions in sublithospheric diamonds from Collier 4 kimberlite pipe, Juina, Brazil: subducted protoliths, carbonated melts and primary kimberlite magmatism. Contrib Mineral Petrol 160:489-510 
Bulanova GP, Zayakina NV (1991) Graphite - iron - cohenite assemblage in the central zone of diamond from 23rd Party Congress kimberlite. Dokl Akad Nauk SSSR 317:706-709

Bundy FP, Bassett WA, Weathers MS, Hemley RJ, Mao HK, Goncharov AF (1996) The pressure-temperature phase and transformation diagram for carbon; updated through 1994. Carbon 34:141-153

Bundy FP, Bovenkerkm HP, Strong HM, Wentorf RH Jr (1961) Diamond-graphite equilibrium line from growth and graphitization of diamond. J Chem Phys 35:383-391

Bundy FP, Kasper JS (1967) Hexagonal diamond - A new form of carbon. J Chem Phys 46:3437

Byrne S, Ingersoll AP (2003) A sublimation model for Martian south polar ice features. Science 299:1051-1053

Catalli K, Williams Q (2005) A high-pressure phase transition of calcite-III. Am Mineral 90:1679-1682

Chalifoux WA, Tykwinski RR (2010) Synthesis of polyynes to model the sp-carbon allotrope carbyne. Nature Chem 2:967-971

Che JW, Cagin T, Goddard WA (1999) Generalized extended empirical bond-order dependent force fields including nonbonded interactions. Theor Chem Acc 102:346-354

Correa AA, Bonev SA, Galli G (2006) Carbon under extreme conditions: Phase boundaries and electronic properties from first-principles theory. Proc Natl Acad Sci 103:1204-1208

Datchi F, Giordano VM, Munsch P, Saitta AM (2009) Structure of carbon dioxide phase IV: Breakdown of the intermediate bonding state scenario. Phys Rev Lett 103:185701

Datchi F, Mallick B, Salamat A, Ninet S (2012) Structure of polymeric carbon dioxide $\mathrm{CO}_{2}-\mathrm{V}$. Phys Rev Lett 108:125701

Davies G (1984) Diamond. Adam Hilger, Bristol, UK

Day HW (2012) A revised diamond-graphite transition curve. Am Mineral 97:52-62

DeCarli PS, Bowden E, Jones AP, Price GD (2002a) Laboratory impact experiments versus natural impact events. GSA Special Paper 356:595-605

DeCarli PS, Bowden E, Sharp TG, Jones AP, Price GD (2002b) Evidence for kinetic effects on shock wave propagation in tectosilicates. Shock Compression of Condensed Matter-2001, Parts 1 and 2, Proceedings 620:1381-1384

Dellago C, Bolhuis PG, Csajka FS, Chandler D (1998) Transition path sampling and the calculation of rate constants. J Chem Phys 108:1964-1977

Dion M, Rydberg H, Schröder E, Langreth DC, Lundqvist BI (2004) Van der Waals density functional for general geometries. Phys Rev Lett 92:246401

Dong JJ, Tomfohr JK, Sankey OF, Leinenweber K, Somayazulu M, McMillan PF (2000) Investigation of hardness in tetrahedrally bonded nonmolecular $\mathrm{CO}_{2}$ solids by density-functional theory. Phys Rev B 62:14685-14689

Downs RT, Somayazulu MS (1998) Carbon dioxide at 1.0 GPa. Acta Crystallogr C 54:897-898

Duclos S, Brister K, Haddon RC, Kortan AR, Thiel FA (1991) Effects of pressure and stress on C $_{60}$ fullerite to $20 \mathrm{GPa}$. Nature 351:380-381

Eggert, JH. Hicks DG, Celliers PM, Bradley DK, McWilliams RS, Jeanloz R, Miller JE, Boehly TR, Collins GW (2010) Melting temperature of diamond at ultra-high pressure. Nature Phys 6:40-43

Endo K, Koizumi S, Otsuka T, Suhara M, Morohasi T, Kurmaev EZ, Chong DP (2001) Analysis of XPS and XES of diamond and graphite by DFT calculations using model molecules. J Comput Chem 22:102-108

Fahy S, Louie SG (1987) High-pressure structural and electronic properties of carbon. Phys Rev B 36:33733385

Fahy S, Louie SG, Cohen ML (1986) Pseudopotential total-energy study of the transition from rhombohedral graphite to diamond. Phys Rev B 34:1191-1199

Finger LW, Hazen RM (1991) Crystal chemistry of six-coordinated silicon: A key to understanding the Earth's deep interior. Acta Crystallogr B 47:561-580

Finger LW, Hazen RM, Fursenko BA (1995) Refinement of the crystal structure of $\mathrm{BaSi}_{4} \mathrm{O}_{9}$ in the benitoite form. J Phys Chem Solids 56:1389-1393

Fiquet G, Badro J, Gregoryanz E, Fei Y, Occelli F (2009) Sound velocity in iron carbide $\left(\mathrm{Fe}_{3} \mathrm{C}\right)$ at high pressure: Implications for the carbon content of the Earth's inner core. Phys Earth Planet Inter 172:125-129

Fiquet G, Guyot F, Kunz M, Matas J, Andrault D, Hanfland M (2002) Structural refinements of magnesite at very high pressure. Am Mineral 87:1261-1265

Frost DJ, Liebske C, Langenhorst F, McCammon CA, Tronnes RG, Rubie DC (2004) Experimental evidence for the existence of iron-rich metal in the Earth's lower mantle. Nature 428:409-412

Frost DJ, McCammon CA (2008) The redox state of Earth's mantle. Annu Rev Earth Planet Sci 36:389-420

Gabrysch M (2008) Electronic properties of diamond. Ph.D. Thesis Uppsala University

Galli G, Martin R, Car R, Parrinello M (1989) Carbon: The nature of the liquid state. Phys Rev Lett 63:988-991

Gathers GR, Shaner JW, Young DY (1974a) High temperature carbon equation of state. UCRL Report 51644, doi: $10.2172 / 4265839$

Gathers GR, Shaner JW, Young DY (1974b) Experimental, very high-temperature, liquid-uranium equation of state. Phys Res Lett 33:70-72 
Gillet, P, Hemley RJ, McMillan PF (1998) Vibrational properties at high pressures and temperatures. Rev Mineral 37:525-590

Giordano VM, Datchi F (2007) Molecular carbon dioxide at high pressure and high temperature. Europhys Lett 77:46002

Giordano VM, Datchi F, Dewaele A (2006) Melting curve and fluid equation of state of carbon dioxide at high pressure and high temperature. J Chem Phys 125:054504

Godard G, Frezzotti ML, Palmeri R, Smith DC (2012) Origin of high-pressure disordered metastable phases (lonsdaleite and incipiently amorphized quartz) in metamorphic rocks: Geodynamic shock or crystalscale overpressure? In: Ultrahigh Pressure Metamorphism: 25 Years After the Discovery of Coesite and Diamond. Dobrzhinetskaya LF, Faryad SW, Wallis S, Cuthbert S (eds) Elsevier, London, p 125-148

Goncharov AF (1990) Carbons at high pressure: Pseudomelting at $44 \mathrm{GPa}$. Zh Eksp Teor Fiz 98:1824

Goodrich CA, Bird JM (1985) Formation of iron-carbon alloys in basaltic magma at Uivfaq, Disko Island: The role of carbon in mafic magmas. J Geology 93:475-492

Guth JR, Hess AC, McMillan PF, Petuskey WT (1990) A valence force field for diamond from ab initio molecular orbital cluster calculations. J Phys Cond Matt 2:8007

Hanfland M, Hu JZ, Shu JF, Hemley RJ, Mao HK, Wu Y (1990) X-ray diffraction and Raman spectroscopy of graphite to 50 GPa. Bull Am Phys Soc 35:465-466

Hanfland M, Syassen K, Sonnenschein R (1989) Optical reflectivity of graphite under pressure. Phys Rev B 40:1951-1954

Hanson RC (1985) A new high-pressure phase of solid $\mathrm{CO}_{2}$. J Phys Chem 89:4499-4501

Hazen RM (1999) The Diamond Makers. Cambridge University Press, New York

Hazen RM, Downs RT, Finger LW (1996) High-pressure framework silicates. Science 272:1769-1771

Hazen RM, Downs RT, Jones AP, Kah L (2013) Carbon mineralogy and crystal chemistry. Rev Mineral Geochem 75:7-46

Hazen RM, Finger LW (1978) Crystal chemistry of silicon-oxygen bonds at high pressure: Implications for the Earth's mantle mineralogy. Science 201:1122-1123

Hazen RM, Mao HK, Finger LW, Bell PM (1980) Structure and compression of crystalline methane at high pressure and room temperature. Appl Phys Lett 37:288-289

He T, Huang Q, Ramirez AP, Wang Y, Regan KA, Rogado N, Hayward MA, Hass MK, Slusky JS, Inumara K, Zandbergen HW, Ong NP, Cava RJ (2001) Superconductivity in the non-oxide perovskite $\mathrm{MgCNi}_{3}$. Nature 411:54-56

Hemley RJ, Dera P (2000) Molecular crystals: high-temperature and high-pressure crystal chemistry. Rev Mineral Geochem 41:335-419

Hirai H, Konagai K, Kawamura T, Yamamoto Y, Yagi T (2008). Phase changes of solid methane under high pressure up to $86 \mathrm{GPa}$ at room temperature. Chem Phys Lett 454:212-217

Hohenberg P, Kohn W (1964) Inhomogeneous electron gas. Phys Rev 136:B864-B871

Holl CM, Smyth JR, Laustsen HMS, Jacobsen SD, Downs RT (2000) Compression of witherite to 8 GPa and the crystal structure of $\mathrm{BaCO}_{3}$ II. Phys Chem Miner 27:467-473

Holm B, Ahuja R, Belonoshko A, Johansson B (2000) Theoretical investigation of high pressure phases of carbon dioxide. Phys Rev Lett 85:1258-1261

Iota V, Yoo CS, Cynn H (1999) Quartzlike carbon dioxide: an optically nonlinear extended solid at high pressures and temperatures. Science 283:1510-1513

Iota V, Yoo CS, Klepeis J, Jenel Z, Evans W, Cynn H (2008) Six-fold coordinated carbon dioxide VI. Nature Mater 6:4-38

Isshiki M, Irifune T, Hirose K, Ono S, Ohishi Y, Watanuki T, Nishibori E, Takadda M, Sakata M (2004) Stability of magnesite and its high-pressure form in the lowermost mantle. Nature 427:60-63

Jacob DE, Kronz A, Viljoen KS (2004) Cohenite, native iron and troilite inclusions in garnets from polycrystalline diamond aggregates. Contrib Mineral Petrol 146:566-576

Jamieson JC (1957) Introductory studies of high-pressure polymorphism to 24,000 bars by $\mathrm{x}$-ray diffraction with some comments on calcite II. J Geol 65:334-343

Javoy M (1997) The major volatile elements of the Earth: Their origin, behavior, and fate, Geophys Res Lett 24:177-180

Jones AP, Claeys P, Heuschkel S (2000) Impact melting of carbonates from the Chicxulub crater. Lecture Notes in Earth Sciences 91:343-361

Jones AP, Dobson D, Wood I, Beard AD, Verchovsky A, Milledge HJ (2008) Iron carbide and metallic inclusions in diamonds from Jagersfontein. 9th International Kimberlite Conference, 9IKC-A-00360

Jones AP, Genge M, Carmody L (2013) Carbonate melts and carbonatites. Rev Mineral Geochem 75:289-322

Jones AP, Kearsley AT, Friend CRL, Robin E, Beard A, Tamura A, Trickett S, Claeys P (2005) Are there signs of a large Paleocene impact, preserved around Disko Bay, West Greenland? Nuussuaq spherule beds origin by impact instead of volcanic eruption? Kenkmann T, Hörz F, Deutsch A (eds) Large Meteorite Impacts III. GSA Special Paper 384: 281-298 
Kaminsky FV, Wirth R (2011) Iron carbide incluisons in lower-mantle diamond from Juina, Brazil. Can Mineral 49:555-572

Kasatochkin VI, Sladkov AM, Kudryavtsev YP, Popov NM, Korshak VV (1967) Crystalline forms of linear modification of carbon. Dokl Akad Nauk SSSR 117:358-360

Kasper JS, Richards SM (1964) The crystal structures of new forms of silicon and germanium. Acta Crystallogr 17:752-755

Keesom WH, Köhler JWL (1934) New determination of the lattice constant of carbon dioxide. Physica 1:167174

Kennedy CS, Kennedy GC (1976) The equilibrium boundary between graphite and diamond. J Geophys Res 81:2467

Keppler H, Wiedenbeck M, Shcheka SS (2003) Carbon solubility in olivine and the mode of carbon storage in the Earth's mantle. Nature 424:414-416

Kerridge JF (1985) Carbon, hydrogen and nitrogen in carbonaceous chondrites. Geochim Cosmochim Acta 49:1707-1714

Kertesz M, Hoffman R (1984) The graphite-to-diamond transformation. J Sol State Chem 54:313-319

Kirillin AV, Kovalenko MD, Scheindlin MA (1984) Heating liquid carbon to $7000 \mathrm{~K}$ with a cw laser. J Exp Theor Phys Lett 40:781-783

Knudson MD, Desjarlais MP, Dolan DH (2008) Shock-wave exploration of the high-pressure phases of carbon. Science 322:1822-1825

Kohn W, Sham LJ (1965) Self-consistent equations including exchange and correlation effects. Phys Rev 140:A1133-A1138

Kurdyumov AV, Britun VF, Yarosh VV, Danlienko AI (2012) The influence of shock compression on the graphite transformations into lonsdaleite and diamond. J Superhard Mater 34:19-27

Lasaga AC, Gibbs GV (1987) Applications of quantum-mechanical potential surfaces to mineral physics calculations. Phys Chem Miner 14:107-117

Lavina B, Dera P, Downs RT, Yang W, Sinogeikin S, Meng Y, Shen G, Schiferl D (2010) Structure of siderite $\mathrm{FeCO}_{3}$ to $56 \mathrm{GPa}$ and hysteresis of its spin-pairing transition. Phys Rev B 82:064110-7

Lavina B, Dera P, Kim E, Meng Y, Downs RT, Weck PF, Sutton SR, Zhao Y (2011) Discovery of the recoverable high-pressure iron oxide $\mathrm{Fe}_{4} \mathrm{O}_{5}$. Proc Natl Acad Sci 108:17281-17284

Lee MS, Montoya JA, Scandolo S (2009) Thermodynamical stability of layered structures in compressed $\mathrm{CO}_{2}$. Phys Rev B 79:144102

Leipunskii OI (1939) On synthetic diamonds. Usp Khim 8:1519

Leoni S, Boulfelfel SE (2010) Pathways of structural transformations in reconstructive phase pransitions: Insights from transition path sampling molecular dynamics. In: Modern Methods of Crystal Structure Prediction. Oganov AR (ed) Wiley-VCH, New York, p 181-221

Li Q, Ma Y, Oganov AR, Wang H, Wang H, Xu Y, Cui T, Mao H-K, Zou G (2009) Superhard monoclinic polymorph of carbon. Phys Rev Lett 102:175506

Liang Q, Yan CS, Meng YF, Lai J, Krasnicki S, Mao HK, Hemley RJ (2009) Enhancing the mechanical properties of CVD single-crystal diamond, J Phys Condens Matter 21:364215

Lin JF, Liu J, Jacobs C, Prakapenka VB (2012) Vibrational and elastic properties of ferromagnesite across the electronic spin-pairing transition of iron. Am Mineral 97:583-591

Litasov KD, Goncharov AF, Hemley RJ (2011) Crossover from melting to dissociation of $\mathrm{CO}_{2}$ under pressure: Implications for the lower mantle. Earth Planet Sci Lett 309:318-323

Liu L (1983) Dry ice II, a new polymorph of $\mathrm{CO}_{2}$. Nature 303:508-509

Lonsdale K (1971) Formation of lonsdaleite from single-crystal graphite. Am Mineral 56:333-336

Lord OT, Walter MJ, Dasgupta R, Clark SM (2009) Melting in the Fe-C system to 70 GPa. Earth Planet Sci Lett 284:157-167

Lovering JF (1964) Electron microprobe analysis of terrestrial and meteoritic cohenite. Geochim Cosmochim Acta 28:1745-1748

Ludwig A (1902) Die schmelzung der kohle. Zeit Elektrochem 8:273

Lyakhov AO, Oganov AR (2011) Evolutionary search for superhard materials applied to forms of carbon and $\mathrm{TiO}_{2}$. Phys Rev B 84:092103

Lyakhov AO, Oganov AR, Valle M (2010) How to predict very large and complex crystal structures. Comput Phys Commun 181:1623-1632

Mao WL, Mao H-K, Eng PJ, Trainor TP, Newville M, Kao C, Heinz DL, Shu J, Meng Y, Hemley RJ (2003) Bonding changes in compressed superhard graphite. Science 302:425-427

Mao Z, Armentrout M, Rainey E, Manning CE, Dera P, Prakapenka VB, Kavner A (2011) Dolomite III: A new candidate lower mantle carbonate. Geophys Res Lett 38:L22303

Marques L, Hodeau JL, Núñez-Regueiro M, Perroux M (1996) Pressure and temperature diagram of polymerized fullerite. Phys Rev B 54:R12633-R12636 
Martinez I, Perez EMC, Matas J, Gillet P, Vidal G (1998) Experimental investigation of silicate-carbonate system at high pressure and high temperature. J Geophys Res-Solid Earth 103:5143-5163

Martinez I, Zhang J, Reeder RJ (1996) In situ X-ray diffraction of aragonite and dolomite at high pressure and high temperature: Evidence for dolomite breakdown to aragonite and magnesite. Am Mineral 81:611-624

Martinez-Canales M, Pickard CJ, Needs RJ (2012) Thermodynamically stable phases of carbon at multiterapascal pressures. Phys Rev Lett 108:045704

Martoňák R, Laio A, Parrinello M (2003) Predicting crystal structures: The Parrinello-Rahman method revisited. Phys Rev Lett 90:075503

Marty B, Alexander CMO'D, Raymond SN (2013) Primordial origins of Earth's carbon. Rev Mineral Geochem 75:149-181

Mason B (1979) Data of Geochemistry, $6^{\text {th }}$ edition. U.S.Geological Survey Prof Paper 440-B-1

Mattila T, Pylkkanen J-P, Rueff S, Huotari G, Vanko M, Hanfland M, Lehtinen M, Hamalainen K (2007) Pressure induced magnetic transition in siderite $\mathrm{FeCO}_{3}$ studied by $\mathrm{X}$-ray emission spectroscopy. J Phys Condens Matter 19:386206_2007

McNeill J, Pearson DG, Klein-David O, Nowell GM, Ottley CJ, Chinn I (2009) Quantitative analysis of trace element concentrations in some gem-quality diamonds. J Phys Condens Matter 21:364207

Merlini M, Crichton WA, Hanfland M, Gemmi M, Mueller H, Kupenko I, Dubrovinsky L (2012) The structures of dolomite at ultrahigh pressure and their influence on the deep carbon cycle. Proc Natl Acad Sci USA 109:13509-13514

Merrill L, Bassett WA (1975) The high-pressure structure of $\mathrm{CaCO}_{3}$ (II), a high-pressure metastable phase of calcium carbonate. Acta Cryst B31:343-349

Mikhail S, Shahar A, Hunt SA, Jones AP, Verchovsky AB (2011) An experimental investigation of the pressure effect on stable isotope fractionation at high temperature; implications for mantle processes and core formation in celestial bodies. 42nd Lunar and Planetary Science Conference, March 7-11 (The Woodlands, TX), http://www.lpi.usra.edu/meetings/lpsc2011/pdf/1376.pdf

Miller ED, Nesting DC, Badding JV (1997) Quenchable transparent phase of carbon. Chem Mater 9:18-22

Mookherjee M (2011) Elasticity and anisotropy of $\mathrm{Fe}_{3} \mathrm{C}$ at high pressures. Am Mineral 96:1530-1536

Mookherjee M, Nakajima Y, Steinle-Neumann G, Glazyrin K, Wu X, Dubrovinsky, L, McCammon C, Chumakov A (2011) High-pressure behavior of iron carbide $\left(\mathrm{Fe}_{7} \mathrm{C}_{3}\right)$ at inner core conditions. J Geophys Res 116:B04201

Murakami M, Hirose K, Kawamura K, Sata N, Ohishi Y (2004) Post-perovskite phase transition in MgSiO $_{3}$. Science 304:855-858

Nevskii NN, Ilyukhin VV, Ivanova LI, Belov NV (1979) Crystal structure of calcium germinate. Sov Phys Dokl 24:135-136

Ni H, Keppler H (2013) Carbon in silicate melts. Rev Mineral Geochem 75:251-287

Niu H, Chen X-Q, Wang S, Li D, Mao WL, LiY (2012) Families of superhard crystalline carbon allotropes constructed via cold compression of graphite and nanotubes. Phys Rev Lett 108:135501

Nuñez Valdez MN, Umemoto K, Wentzkovitch RM (2012) Elasticity of diamond at high pressures and temperatures. Appl Phys Lett 100:171902

Núñez-Regueiro M, Monceau P, Hodeau JL (1992) Crushing $\mathrm{C}_{60}$ to diamond at room temperature. Nature 355:237-239

Occelli F, Loubeyre P, LeToullec R (2003) Properties of diamond under hydrostatic pressures up to $140 \mathrm{GPa}$. Nature Mater 2:151-154

Oganov AR (ed) (2010) Modern Methods of Crystal Structure Prediction. Wiley-VCH, Berlin

Oganov AR, Chen J, Gatti C, Ma Y-Z, Ma YM, Glass CW, Liu Z, Yu T, Kurakevych OO, Solozhenko VL (2009) Ionic high-pressure form of elemental boron. Nature 457:863-867

Oganov AR (ed) (2010). Modern Methods of Crystal Structure Prediction. Berlin: Wiley-VCH

Oganov AR, Glass CW (2006) Crystal structure prediction using ab initio evolutionary techniques: principles and applications. J Chem Phys 124:244704

Oganov AR, Glass CW, Ono S (2006) High-pressure phases of $\mathrm{CaCO}_{3}$ : crystal structure prediction and experiment. Earth Planet Sci Lett 241:95-103

Oganov AR, Lyakhov AO, Valle M (2011) How evolutionary crystal structure prediction works - and why. Acc Chem Res 44:227-237

Oganov AR, Ma Y, Lyakhov AO, Valle M, Gatti C (2010) Evolutionary crystal structure prediction as a method for the discovery of minerals and materials. Rev Mineral Geochem 71:271-298

Oganov AR, Ono S (2004) Theoretical and experimental evidence for a post-perovskite phase of $\mathrm{MgSiO}_{3}$ in Earth's D" layer. Nature 430:445-448

Oganov AR, Ono S, Ma Y, Glass CW, Garcia A (2008) Novel high-pressure structures of $\mathrm{MgCO}_{3}, \mathrm{CaCO}_{3}$ and $\mathrm{CO}_{2}$ and their role in the Earth's lower mantle. Earth Planet Sci Lett 273:38-47

Olijnyk H, Dauefer H, Jodl HJ, Hochheimer HD (1988) Effect of pressure and temperature on the Raman spectra of solid $\mathrm{CO}_{2}$. J Chem Phys 88:4204-4212 
Olijnyk H, Jephcoat AP (1998) Vibrational studies on $\mathrm{CO}_{2}$ up to $40 \mathrm{GPa}$ by Raman spectroscopy at room temperature. Phys Rev B 57:879-888

Ono S, Kikegawa T, Ohishi Y (2007) High-pressure phase transition of $\mathrm{CaCO}_{3}$. Am Mineral 92:1246-1249

Ono S, Kikegawa T, Ohishi Y, Tsuchiya J (2005) Post-aragonite phase transformation in $\mathrm{CaCO}_{3}$ at $40 \mathrm{GPa}$. Am Mineral 90:667-671

Origlieri MJ, Yang H, Downs RT, Posner ES, Domanik KJ, Pinch WJ (2012) The crystal structure of bartelkeite, with a revised chemical formula, $\mathrm{PbFeGe}{ }^{\mathrm{VI}}\left(\mathrm{Ge}^{\mathrm{IV}}{ }_{2} \mathrm{O}_{7}\right)(\mathrm{OH})_{2} \cdot \mathrm{H}_{2} \mathrm{O}$, isotypic wth high-pressure $P 2_{1} / m$ lawsonite. Am Mineral 97:1812-1815

Pan Z, Sun H, Zhang Y, Chen C (2009) Harder than diamond: superior indentation strength of wurtzite BN and lonsdaleite. Phys Rev Lett 102:055503

Panero R, Kabbes JE (2008) Mantle-wide sequestration of carbon in silicates and the structure of magnesite II. Geophys Res Lett 35:L14307

Park JH, Yoo CS, Iota V, Cynn H, Nicol MF, Le Bihan T (2003) Crystal structure of bent carbon dioxide phase IV. Phys Rev B 68:014107

Perdew JP, Bruke K, Ernzerhof M (1996) Generalized gradient approximation made simple. Phys Rev Lett 78:3865-3868

Perdew JP, Wang Y (1992) Accurate and simple analytic representation of the electron-gas correlation energy. Phys Rev B 45:13244-13249

Pickard CJ, Needs RJ (2011) Ab initio random structure searching. J Phys Condens Matter 23:053201

Raman CV (1962) The infra-red absorption by diamond and its significance. Part I. Materials and Methods. Proc Indian Acad Sci A 55:1-4

Ramaswamy C (1930) Raman effect in diamond. Nature 125:704

Ringwood AE (1960) Cohenite as a pressure indicator in oron meteorites. Geochim Cosmochim Acta 20:155158

Robbins C, Perloff A, Block S (1968) Crystal structure of $\mathrm{BaGe}\left[\mathrm{Ge}_{3} \mathrm{O}_{9}\right]$ and its relation to benitoite. J Res Natl Bureau Standards A 70:385-391

Rohrbach A, Ballhaus C, Golla-Shindler U, Ulmer P, Kamenetsky VS, Kuzmin DV (2007) Metal saturation in the upper mantle. Nature 449:456-458

Rohrbach A, Ballhaus C, Ulmer P, Golla-Schindler U, Schonbohm D (2010) Experimental evidence for a reduced metal-saturated upper mantle. J Petrol 52:717-731

Rohrbach A, Schmidt MW (2011) Redox freezing and melting in the Earth's deep mantle resulting from carboniron redox coupling. Nature 472:209-212

Roman-Perez G, Soler JM (2009) Efficient implementation of a van der Waals density functional: Application to double-wall carbon nanotubes. Phys Rev Lett 103:096102

Ross A, Steele A, Fries MD, Kater L, Downes H, Jones A P, Smith CL, Jeniskens PM, Zolensky ME, Shaddad MH (2011) MicroRaman spectroscopy of diamond and graphite in Almahata Sitta and comparison with other ureilites. Meteor Planet Sci 46:364-378

Rossini FD, Jessup RS (1938) Heat and free energy formation of carbon dioxide and the transition between graphite and diamond. J Natl Bureau Standards C 21:491-513

Rouquette J, Dolejs D, Kantor IY, McCammon CA, Frost DJ, Prakapenka VB, Dubrovinsky LS (2008) Ironcarbon interactions at high temperatures and pressures. Appl Phys Lett 92:121912-121913

Santillán J, Williams Q, Knittle E (2003) Dolomite-II: A high-pressure polymorph of $\mathrm{CaMg}\left(\mathrm{CO}_{3}\right)_{2}$. Geophys Res Lett 30:1054-1059

Santoro M, Gorelli F, Bini R, Haines J, Cambon O, Levelut C, Montoya JA, Scandolo S (2012). Partially collapsed cristobalite structure in the non molecular phase V in $\mathrm{CO}_{2}$. Proc Natl Acad Sci USA 109:51765179

Santoro M, Gorelli F, Haines J, Cambon O, Levelut C, Garbarino G (2011) Silicon carbonate phase formed from carbon dioxide and silica under pressure. Proc Nat Acad Sci 108:7689-7692

Santoro M, Gorelli FA, Bini R, Ruocco G, Scandolo S, Crichton WA (2006) Amorphous silica-like carbon dioxide. Nature 441:857-860

Sata N, Hirose K, Shen G, Nakajima Y, Ohishi Y, Hirao N (2010) Compression of $\mathrm{FeSi}, \mathrm{Fe}_{3} \mathrm{C}, \mathrm{Fe}_{0.95} \mathrm{O}$, and $\mathrm{FeS}$ under the core pressure and implication for light element in the Earth's core, J Geophys Res 115:B09204

Sato K, Katsura T (2001) Experimental investigation on dolomite dissociation into aragonite + magnesite up to 8.5 GPa. Earth Planet Sci Lett 184:529-534

Saunders M, Cross RJ, Jiménez-Vázquez HA, Shimshi R, Khong A (1996) Noble gas atoms inside fullerenes. Science 271:1693-1697

Savvatimskiy AI (2005) Measurements of the melting point of graphite and the properties of liquid carbon (a review for 1963-2003). Carbon 43:1115-1142

Scott HP, Williams Q, Knittle E (2001) Stability and equation of state of $\mathrm{Fe}_{3} \mathrm{C}$ to $73 \mathrm{GPa}$ : Implications for carbon in the Earth's core. Geophys Res Lett 28:1875-1878 
Selli D, Baburin IA, Martoňák R, Leoni S (2011) Superhard $\mathrm{sp}^{3}$ carbon allotropes with odd and even ring topologies. Phys Rev B 84:161411

Sengupta A, Yoo CS (2009) Coesite-like $\mathrm{CO}_{2}$ : a missing analog to $\mathrm{SiO}_{2}$. Phys Rev B 80:014118

Sephton MA, Hazen RM (2013) On the origins of deep hydrocarbons. Rev Mineral Geochem 75:449-465

Serra S, Cavazzoni C, Chiarotti GL, Scandolo S, Tosatii E (1999) Pressure-induced solid carbonates from molecular $\mathrm{CO}_{2}$ by computer simulation. Science 284:788-790

Seto Y, Hamane D, Nagai T, Fujino F (2008) Fate of carbonates within oceanic plates subducted to the lower mantle, and a possible mechanism of diamond formation. Phys Chem Miner 35:223-229

Shin K, Kumar R, Udachin KA, Alavi S, Ripmeester JA (2012) Ammonia clathrate hydrates as new solid phases for Titan, Enceladus, and other planetary systems. Proc Natl Acad Sci 109:14785-14790

Shumilova TG, Mayer R, Isaenko SI (2011) Natural monocrystalline lonsdaleite. Dokl Earth Sci 441:1552-1554

Simakov SK (2010) Metastable nanosized diamond formation from a C-H-O fluid system. J Mater Res 25:23362340

Skorodumova NV, Belonoshko AB, Huang L, Ahuja R, Johansson B (2005) Stability of the $\mathrm{MgCO}_{3}$ structures under lower mantle conditions. Am Mineral 90:1008-1011

Smith R (2011) Ramp compression of carbon above 50 Mbar on NIF. Bull Am Phys Soc 56:BAPS.2011.DPP. TI3.5, http://meetings.aps.org/link/BAPS.2011.DPP.TI3.5

Smolin Yu-I (1969) Crystal structure of barium tetragermanate Sov Phys Dokl 13:641

Smyth JR (2006) Hydrogen in high pressure silicate and oxide mineral structures. Rev Mineral Geochem 62:85116

Smyth JR, Jacobsen SD (2006) Nominally anhydrous minerals and Earth's deep water cycle. In: Earth's Deep Water Cycle. van der Lee S, Jacobsen SD (ed) American Geophysical Union Monograph Series 168:1-11

Stachel T, Harris JW, Brey GP (1998) Rare and unusual mineral inclusions in diamonds from Mwadui, Tanzania. Contrib Mineral Petrol 132:34-47

Stagno V, Frost DJ (2011) Carbon speciation in the asthenosphere: Experimental measurements of the redox conditions at which carbonate-bearing melts coexist with graphite or diamond in peridotite assemblages. Earth Planet Sci Lett 300:72-84

Suito K, Namba J, Horikawa T, Taniguchi Y, Sakurai N, Kobayashi M, Onodera A, Shimomura O, Kikegawa T (2001) Phase relations of $\mathrm{CaCO}_{3}$ at high pressure and high temperature. Am Mineral 86:997-1002

Sun J, Klug DD, Martoňák R, Montoya JA, Lee M-S, Scandola S, Tosatti E (2009) High-pressure polymeric phases of carbon dioxide. Proc Natl Acad Sci USA 106:6077-6081

Sun J, Klug DD, Pickard CJ, Needs RJ (2011) Controlling the bonding and band gaps of solid carbon monoxide with pressure. Phys Rev Lett 106:145502

Sundqvist B (1999) Fullerenes under high pressures. Adv Phys 48:1-134

Swanson DK, Prewitt CT (1983) The crystal structure of $\mathrm{K}_{2} \mathrm{Si}^{\mathrm{VI}} \mathrm{Si}_{3}{ }^{\mathrm{IV}} \mathrm{O}_{9}$. Am Mineral 68:581-585

Tao JM, Perdew JP, Staroverov VN, Scuseria GE (2003) Climbing the density functional ladder: Nonempirical meta-generalized gradient approximation designed for molecules and solids. Phys Rev Lett 91:146401

Terasaki H, Nishida K, Shibazaki Y, Sakamaki T, Suzuki A, Ohtani E, Kikegawa T (2010) Density measurement of $\mathrm{Fe}_{3} \mathrm{C}$ liquid using $\mathrm{x}$-ray absorption image up to $10 \mathrm{GPa}$ and effect of light elements on compressibility liquid iron. J Geophys Res 115:B06207

Tschauner O, Mao HK, Hemley RJ (2001) New transformations of $\mathrm{CO}_{2}$ at high pressures and temperatures. Phys Rev Lett 87:075701

Tulk CA, Klug DD, dos Santos AM, Karotis G, Guthrie M, Molaison JJ, Pradhan N (2012) Cage occupancies in the high pressure structure H methane hydrate: A neutron diffraction study. J Chem Phys 136:054502

Umemoto K, Wentzcovitch RM, Saito S, Miyake T (2010) Body-centered tetragonal $\mathrm{C}_{4}$ : A viable sp ${ }^{3}$ carbon allotrope. Phys Rev Lett 104:125504

Utsumi W, Yagi T (1991) Light-transparent phase formed by room-temperature compression of graphite. Science 252:1542-1544

Utsumi W, Yagi T, Taniguchi T, Shimomura O (1996) In situ x-ray observation of the graphite-diamond transition using synchrotron radiation. Proc $3^{\mathrm{d}}$ NIRIM International Symposium on Advanced Materials, 257-261

Utsumi W, Yamakata M, Yagi T, Shimomura O (1994) Diffraction study of the phase transition from graphite to hexagonal diamond under high pressures and high temperatures. In: Proceedings of the 14th AIRAPT Conference, Colorado Springs, CO. Schmidt SC, Shaner JW, Samara GA, Ross M (eds) Am Inst Phys Conf Proceedings 309:535-538

Utsumi W, Yamakata M, Yagi T, Shimomura O (1993) In situ x-ray diffraction study of the phase transition from graphite to hexagonal diamond under high pressures and high temperatures. In: High Pressure Science and Technology. AIP Conference Proceedings 309:535-538, doi: 10.1063/1.46474

Wang JT, Chen C, Kawazoe Y (2011). Low-temperature phase transformation from graphite to $\mathrm{sp}^{3}$ orthrhombic carbon. Phys Rev Lett 106:075501

Wang L, Liu B, Li H, Yang W, Ding Y, Sinogeiken SV, Meng Y, Liu Z, Zeng XC, Mao WL (2012a) Long-range ordered carbon clusters: A crystalline material with amorphous building blocks. Science 337:825-828 
Wang Y, Panzik JE, Kiefer B, Lee KKM (2012b) Crystal structure of graphite under room-temperature compression and decompression. Sci Reports 2:520

Wang ZW, Zhao YS, Tait K, Liao XZ, Schiferl D, Zha CS, Downs RT, Qian J, Zhu YT, Shen TD (2004) A quenchable superhard carbon phase synthesized by cold compression of carbon nanotubes. Proc Natl Acad Sci USA 101:13699-13702

Weck G, Desgreniers S, Loubeyre P, Mezouar M (2009) Single-crystal structural characterization of the metallic phase of oxygen. Phys Rev Lett 102:255503

Weerasinghe GL, Needs RJ, Pickard CJ (2011) Computational searches for iron carbide in the Earth's inner core. Phys Rev B 84:174110

Wen XD, Hand L, Labet V, Yang T, Hoffmann R, Ashcroft NW, Oganov AR, Lyakhov AO (2011) Graphane sheets and crystals under pressure. Proc Natl Acad Sci USA 108:6833-6837

Wood BJ, Li J, Shahar A (2013) Carbon in the core: its influence on the properties of core and mantle. Rev Mineral Geochem 75:231-250

Xie Y, Oganov AR, Ma Y (2010) Novel structures and high pressure superconductivity of CaLi2 . Phys Rev Lett 104:177005

Yagi T, Utsumi W, Yamakata M, Kikegawa T, Shimomura O (1992) High-pressure in situ x-ray diffraction study of the phase transformation from graphite to hexagonal diamond at room temperature. Phys Rev B 46:6031

Yoo CS, Cynn H, Gygi F, Galli G, Iota V, Nicol M, Carlson S, Hausermann D, Mailhiot C (1999). Crystal structure of carbon dioxide at high pressure: "Superhard" polymeric carbon dioxide. Phys Rev Lett 83:5527-5530

Zhang Y, Yin QZ (2012) Carbon and other light elements contents in the Earth's core based on first-principles molecular dynamics. Proc Natl Acad Sci 109:19579-19583

Zhao YX, Spain IL (1989). X-ray diffraction data for graphite to 20 GPa. Phys Rev B 40:993

Zhao Z, Bu X, Wang, LM, Wen B, He J, Liu Z, Wang HT, Tian Y (2011), Novel superhard carbon: C-centered orthorhombic $\mathrm{C}_{8}$. Phys Rev Lett 107:215502

Zhou XF, Qian GR, Dong X, Zhang L, Tian Y, Wang HT (2010). Ab initio study of the formation of transparent carbon under pressure. Phys Rev B 82:134126

Zhu Q, Oganov AR, Lyakhov AO (2012a) Evolutionary metadynamics: a novel method to predict crystal structures. Cryst Eng Commun 14:3596-3601

Zhu Q, Oganov AR, Salvado M, Pertierra P, Lyakhov AO (2011) Denser than diamond: ab initio search for superdense carbon allotropes. Phys Rev B 83:193410

Zhu Q, Zeng Q, Oganov AR (2012b) Systematic search for low-enthalpy sp ${ }^{3}$ carbon allotropes using evolutionary metadynamics. Phys Rev B 84:201407

Zhu Y, Ogasawara Y (2002) Carbon recycled into deep Earth: Evidence from dolomite dissociation in subductionzone rocks. Geology 30: 947-950 
